\title{
Teleost and elasmobranch eye lenses as a target for life- history stable isotope analyses
}

Katie Quaeck-Davies ${ }^{1}$, Victoria A Bendall ${ }^{2}$, Kirsteen M MacKenzie ${ }^{3}$, Stuart Hetherington ${ }^{2}$, Jason Newton ${ }^{4}$, Clive N Trueman ${ }^{\text {Corresp. } 1}$

1 Ocean and Earth Science, University of Southampton, Southampton, United Kingdom

2 Centre for Environment, Fisheries and Aquaculture Science, Lowestoft, United Kingdom

3 Institute of Marine Research/Havforskningsinstituttet, Bergen, Norway

4 Scottish Universities Environmental Research Centre, University of Glasgow, Glasgow, United Kingdom

Corresponding Author: Clive N Trueman

Email address: trueman@noc.soton.ac.uk

Incrementally grown, metabolically inert tissues such as fish otoliths provide biochemical records that can used to infer behavior and physiology throughout the lifetime of the individual. Organic tissues are particularly useful as the stable isotope composition of the organic component can provide information about diet, trophic level and location. Unfortunately, inert, incrementally grown organic tissues are relatively uncommon. The vertebrate eye lens, however, is formed via sequential deposition of protein-filled fiber cells, which are subsequently metabolically inert. Lenses therefore have the potential to serve as biochemical data recorders capturing life-long variations in dietary and spatial ecology. Here we review the state of knowledge regarding the structure and formation of fish eye lenses in the context of using lens tissue for retrospective isotopic analysis. We discuss the relationship between eye lens diameter and body size, describe the successful recovery of expected isotopic gradients throughout ontogeny and between species, and quantify the isotopic offset between lens protein and white muscle tissue. We show that fish eye lens protein is an attractive host for recovery of stable isotope life histories, particularly for juvenile life stages, and especially in elasmobranchs lacking otoliths, but interpretation of lens-based records is complicated by species-specific uncertainties associated with lens growth rates. 
1 Teleost and elasmobranch eye lenses as a target for life-history stable isotope

2 analyses.

3 Katie Quaeck-Davies ${ }^{1}$, Victoria A. Bendall ${ }^{2}$, Kirsteen M. MacKenzie ${ }^{3}$, Stuart Hetherington ${ }^{2}$,

4 Jason Newton ${ }^{4}$, Clive N. Trueman ${ }^{1}$

$5 \quad{ }^{1}$ Ocean and Earth Science, University of Southampton, Southampton, UK

$6 \quad{ }^{2}$ Centre for Environment, Aquaculture and Fisheries Science, Lowestoft, Suffolk, UK

$7 \quad{ }^{3}$ Institute of Marine Research/Havforskningsinstituttet, Bergen, Norway

$8 \quad{ }^{4}$ Scottish Universities Environmental Research Centre, University of Glasgow, Glasgow, UK

9

10

11 Corresponding Author:

12 Clive Trueman ${ }^{1}$

13 Email address: trueman@noc.soton.ac.uk

14

15

16

17 
19 Abstract

20 Incrementally grown, metabolically inert tissues such as fish otoliths provide biochemical

21 records that can used to infer behavior and physiology throughout the lifetime of the

22 individual. Organic tissues are particularly useful as the stable isotope composition of the

23 organic component can provide information about diet, trophic level and location.

24 Unfortunately, inert, incrementally grown organic tissues are relatively uncommon. The

25 vertebrate eye lens, however, is formed via sequential deposition of protein-filled fiber

26 cells, which are subsequently metabolically inert. Lenses therefore have the potential to

27 serve as biochemical data recorders capturing life-long variations in dietary and spatial 28 ecology.

29

30 Here we review the state of knowledge regarding the structure and formation of fish eye

31 lenses in the context of using lens tissue for retrospective isotopic analysis. We discuss the

32 relationship between eye lens diameter and body size, describe the successful recovery of 33 expected isotopic gradients throughout ontogeny and between species, and quantify the 34 isotopic offset between lens protein and white muscle tissue. We show that fish eye lens 35 protein is an attractive host for recovery of stable isotope life histories, particularly for 36 juvenile life stages, and especially in elasmobranchs lacking otoliths, but interpretation of 37 lens-based records is complicated by species-specific uncertainties associated with lens 38 growth rates. 
42

43

\section{Introduction}

44 Retrospective chemical analyses of inert, incrementally formed tissues provide valuable 45 insights into (for instance) the trophic and spatial ecology of animals (i.e. their trophic 46 47 48 49 geography)(Best and Schell, 1996; Bird et al., 2018), population connectivity and stock structure (Campana, 1999) and interactions between animals and climate (Trueman et al., 2012). This source of information can be particularly useful for elusive marine animals where direct observation and physical tagging is complicated by large spatial distances and inaccessible habitats.

Incrementally grown tissues are commonly used for retrospective biochemical assessment (Tzadik et al., 2017). The trace element and stable isotope chemistry of otolith aragonite has been used extensively to provide a chronological chemical record of the water inhabited by the fish (e.g. Kalish, 1991; Thorrold et al., 1997; Campana, 1999; Høie et al., 2004, Tzadik et al., 2017), addressing questions such as stock mixing and nursery origin of Atlantic bluefin tuna (Thunnus thynnus) (Schloesser et al. 2010), ontogenetic depth migration in the roundnose grenadier (Coryphaenoides rupestris) (Longmore et al., 2011) and migration in Atlantic salmon (Salmo salar) (Hanson et al. 2010). However such inorganic records do not provide information on trophic ecology. Recently, isotopic analyses of the organic component of otoliths (Grønkjær et al., 2013) open the potential for retrospective reconstruction of ontogenetic variation in feeding and spatial ecology of individual fishes, but the sample sizes required currently limit the application of the method. The isotopic composition of carbon and nitrogen in incrementally grown organic 
64 tissues such as baleen (Best \& Schell, 1996; Hobson \& Schell, 1998; Lee et al., 2005),

65 vertebral collagen (Estrada et al., 2006; Kim et al. 2012) and vibrissae (Cherel et al. 2009)

66 is particularly attractive as an ecological tracer (Tzadik et al., 2017). Variations in stable

67 isotope compositions of carbon, nitrogen and sulfur within incrementally-grown tissues

68 can be interpreted with respect to changes in diet or trophic level and/or variation in the

69 isotopic composition of primary production across areas or habitats (the isotopic baseline).

70 The vertebrate eye lens is another incrementally grown, metabolically inert, proteinacous

71 tissue and as such is potentially suitable for retrospective recovery of life history

72 biochemical data (Dove \& Kingsford, 1998; Kingsford \& Gillanders, 2000; Gillanders, 2001,

73 Parry 2003, Wallace et al., 2014; Tzadik et al., 2017.). The vertebrate eye lens has received

74 comparatively little attention as a host for life history biochemical data (Parry 2003,

75 Wallace et al., 2014). Effective use of the eye lens as a tissue for hosting isotope data

76 depends on knowledge of the structure, growth and isotopic systematics of lens proteins. In

77 this study we briefly review the structure and growth of fish eye lenses, test the

78 performance of lens-hosted stable isotope compositions to recover known or expected

79 isotopic contrasts within and between species, and outline where additional information is

80 needed to fully exploit the lens-based isotope archive.

81 Structure and formation of the vertebrate eye lens

82 The cellular structure of the vertebrate eye lens is conserved across taxa, despite evolving

83 to suit numerous ecological niches (Blundell et al. 1981). Within the eye, lenses are cellular

84 organs that serve as a focusing device, allowing images to form on the retina. In order to

85 fulfill this role, lenses must be transparent and have a high refractive index (Bloemendal et 
86 al. 2004, Kroger, 2013). Growth of the lens begins during early embryonic development

87 (Grainger, 1992) and stems from the ectoderm that overlies the optic cup, which

88 subsequently inverts and pinches off to form a hollow vesicle (Bassnett \& Beebe, 1992;

89 Bloemendal et al. 2004). Cells occupying the posterior region of the lens elongate to form

90 primary lens fiber cells, which subsequently fill the vesicle (Bloemendal et al., 2004). The

91 anterior region of the lens comprises a monolayer of epithelial cells which divide in a

92 region located anterior to the equator (Bloemendal et al., 2004). Newly formed cells

93 elongate forming secondary fiber cells, which overlay the primary fibers (Bron et al., 2000;

94 Kroger, 2013). Cells in the same layer connect at the poles of the lens in an area referred to

95 as the suture plane. Suture planes result in some light scattering even in healthy lenses, and

96 are believed to serve as pathways of extracellular transport (Vaghefi et al. 2012).

97 Fiber cells are densely packed and arranged in concentric layers with older cells occupying

98 the central core region, and younger cells sequentially added on top (Bloemendal et al.,

99 2004, Kroger 2013). This process continues throughout the lifetime of all vertebrates,

100 including humans (Augusteyn, 2010), resulting in a lifetime increases in tissue volume

101 (Bassnett \& Beebe, 1992), although critically, lens growth rate reduces throughout

102 ontogeny (Bron et al., 2000), potentially producing near isometric growth of lens diameter

103 compared to total body size. During fiber cell differentiation, protein-coding genes are

104 expressed in a regular manner resulting in variable relative proportions of proteins

105 between the core/nucleus and outer cortex (Bloemendal et al., 2004). These soluble

106 proteins are collectively referred to as the crystallins. During the last phase of fiber cell

107 differentiation, degradation of the membrane-bound organelles occurs in a process which

108 closely resembles the early stages of apoptosis (Bassnett, 2002). Loss of nuclei, 
109 mitochondria and ribosomes removes potential light scattering objects, and is necessary

110 for the lens to achieve transparency (Bassnett \& Beebe, 1992a; Bassnett, 2002; Bloemendal

111 et al., 2004). Primary fiber cells are the first to lose their organelles, resulting in an

112 organelle free zone (OFZ) (Bassnett, 2002). As development proceeds, the OFZ also

113 envelops secondary fiber cells (Bassnett, 2002). In fishes, the depth horizon of fiber cell

114 denucleation is approximately $90 \%$ of the lens radius (Schartau et al., 2009). Beyond the

$115 \mathrm{OFZ}$, in the outer c.10\% of the lens radius, the process of cell denucleation is incomplete.

116 After the loss of organelles, fiber cells can no longer synthesize or degrade proteins, and

117 crystalline proteins therefore persist throughout the organism's lifetime (Bloemendal et al., 118 2004).

120 Lens proteins

121 Lens fiber cells have an unusually high cytosolic protein content which, in fish, varies from 122 approximately $0.13 \mathrm{~g} \mathrm{ml}^{-1}$ at the outer edge to $1.05 \mathrm{~g} \mathrm{ml}^{-1}$ at the core (Bloemendal et al., 123 2004). All vertebrate lenses contain $\alpha, \beta$ and $\gamma$ crystalline proteins, commonly known to as

124 the classic or ubiquitous crystallins (Lynnerup et al., 2008; Bloemendal et al., 2004). Other 125 crystalline proteins exist within the lens, however these are taxon-specific (Bloemendal et 126 al., 2004). The increasing refractive gradient from lens edge to core is associated with the 127 water content and protein concentration of the fiber cells. Water content is controlled by 128 regulation and post-translational modification of aquaporin-0 (Ball et al., 2004; Hedfalk et 129 al., 2006; Törnroth-Horsefield et al., 2010; Gutierrez et al., 2011). The core region of the 130 lens has a high protein and low water content, and is often hard and incompressible 
131 (Fernald, 1985), Bloemendal et al., 2004). Once the proteins have obtained this high

132 concentration, they are generally not re-soluble (Bloemendal et al., 2004) and the nucleus

133 achieves a uniform, relatively high, refractive index (Fernald, 1985). Moving away from the

134 core, cytosolic protein concentration decreases (Philipson, 1969), and water content

135 increases, resulting in the reduction in the refractive index. Close to the lens surface,

136 cytosolic protein concentration decreases rapidly (Kroger, 2013). This results in a steep

137 refractive gradient between the outer edge of the core region, and the outer cortex

138 (Fernald, 1985). This gradient is essential in order to maintain visual functioning in fishes

139 as the cornea provides no refractive power in water (de Busserolles et al. 2013).

140 Consequently in fully aquatic animals the lens, with its variable refractive gradient from

141 core to edge, is solely responsible for light refraction, and is generally spherical or sub-

142 spherical in fishes (Nicol, 1989). Proteins must therefore exist both in a concentrated solid

143 state in the core, and a gelatinous solution at the outer cortex (Lynnerup et al., 2008),

144 producing a tissue consisting of two physically distinct zones (Fernald, 1985). The shape of

145 the outer cortex is maintained by the lens capsule (Fernald, 1985), whereas the central

146 core region is a dense, stable structure. In the eye, the epithelial basement membrane

147 completely encloses the lens, resulting in the absence of blood vessels (Lynnerup et al.,

148 2008). Desquamation of ageing cells is therefore restricted as no metabolites are

149 transported to the lens, preventing cell degradation (Beebe, 2003). Thus, the protein-filled

150 lens fiber cells are not remodeled throughout ontogeny. The eye lens is thus a sequentially

151 formed, metabolically inert tissue, almost pure protein, and suitable for hosting 152 ontogenetic biochemical information. 
154 The potential for deriving life history information from the inert, organic, and

155 incrementally formed fish eye lens has been explored, albeit less intensively than for other

156 incrementally grown tissues Tzadik et al., (2017). The trace element composition of eye

157 lenses has been studied in the context of fish migration and stock discrimination studies

158 (Dove \& Kingsford, 1998; Kingsford \& Gillanders, 2000; Gillanders, 2001). Differences in

159 absolute and relative trace element compositions between lens, otolith and other

160 biomineralised tissues were found, as expected based on the fundamental chemical

161 differences between host matrices (proteins compared to mineral lattices). Lenses are

162 exposed to the aqueous humor implying potential for post deposition post-depositional

163 exchange of weakly-bonded ions, particularly considering the potentially relatively

164 permeable nature of lens proteins (Dove \& Kingsford, 1998, Tzadik et al., 2017). While

165 lenses may be a less suitable host than otoliths for the more ionically-bonded metal ions

166 such as $\mathrm{Sr}, \mathrm{Mg}$ and Ba which form the bulk of otolith microchemical work, Covalently

167 bonded ions such as $\mathrm{Pb}$ and Hg maybe more strongly bonded to proteins, and thus more

168 effectively recorded in lens tissues. The trace element composition of eye lenses has

169 received relatively little attention despite calls to consider lenses as suitable targets,

170 particularly for covalently bound metal ions (Dove \& Kingsford, 1998, Tzadik et al., 2017).

171

172 The stable isotope composition of carbon and nitrogen in lens proteins has been explored

173 in an attempt to reconstruct feeding chronologies in squid (Parry, 2003; Hunsicker et al.,

174 2010; Onthank, 2013). Parry (2003) identified an increasing trend in $\delta^{15} \mathrm{~N}$ values with body

175 size in sequential samples of lens proteins from Ommastrephes bartramii and Sthenoteuthis

176 oualaniensis, suggesting that ontogenetic trophic shifts are reflected and preserved within 
177 eye lens chemistry. Whilst Onthank (2013) identified no common ontogenetic trend in

178 stable isotope composition among squid, individual specimens did exhibit ontogenetic

179 variations in the stable nitrogen isotope composition of lens proteins, suggesting changes

180 in diet over the individual's lifetime. Hunsicker (2010) applied similar methodologies to

181 study the commander squid (Berryteuthis magister) in the eastern Bering Sea, identifying

182 an increase of $\sim 1$ trophic position between juvenile and adult life stages. A similar

183 approach was adopted to demonstrate recovery of whole-life stable isotope records from

184 teleost fishes (Wallace et al., 2014). Red grouper (Epinephelus morio), gag (Mycteroperca

185 microlepis), red snapper (Lutjanus campechanus), and white grunt (Haemulon plumierii)

186 lenses were examined, showing consistency between left and right eye lenses, and

187 recovering increasing $\delta^{15} \mathrm{~N}$ values from lens nucleus (core) to cortex, as expected given

188 anticipated increases in trophic position with size or age. The inert nature of lens core

189 proteins formed in the early juvenile period also opens the potential for radiocarbon-based

190 age estimation. Lynnerup et al. (2008) and Kjeldsen et al. (2010) both reported successful

191 application of bomb radiocarbon dating to human eye lenses. More recently, Nielsen et al.

192 (2016) used radiocarbon dating on the eye lens nuclei of 28 female Greenland sharks

193 (Somniosus microcephalus), estimating longevity to be on the order of hundreds of years.

194

195 Elasmobranchs do not possess large, calcified otoliths suitable for age determination and 196 ontogenetic investigation (Cailliet and Goldman, 2004), consequently life histories of 197 elasmobranchs are generally much more poorly understood than those of teleosts. 198 Elasmobranch vertebrae and fin spines grow incrementally, and can offer 199 sclerochronological detail, providing most of the known methods to age elasmobranchs 
200 (Cailliet and Goldman, 2004). However many elasmobranchs do not have fin spines, and 201 poorly mineralized vertebrae present challenges for accurate and precise age 202 determination. Vertebrae do offer a medium for retrospective isotopic analysis (e.g. Kim et 203 al., 2012), but many species have small vertebrae, and the mass requirements of analysis 204 coupled with the difficulty of relating vertebral position to body size or age, and the need to 205 remove carbonated bioapatite from mineralized vertebral samples limits the number of 206 samples available for ontogenetic study, ultimately reducing temporal resolution. 207 Functioning eyes are generally essential for hunting in most fishes, and there is selective 208 pressure to develop eyes early in ontogeny. Eye lenses may therefore be particularly well 209 suited to the reconstruction of early life history ecology in fishes. In many elasmobranchs, 210 the yolk or placenta provides nourishment to the developing pup prior to emergence from 211 the egg case (oviparous) or birth (viviparous/aplacental viviparous) (Hamlett et al., 1993). 212 Nutrient assimilation driving embryonic development in elasmobranchs is thus 213 characterized principally by the chemical properties of the prey of mature females during 214 gestation or the period of yolk sac formation. The chemical composition of core regions of 215 incrementally grown tissues of elasmobranchs therefore reflects maternal trophic 216 geography during egg formation. The isotopic record at the core of the eye lens is 217 particularly interesting as mature female elasmobranchs are often elusive, and therefore 218 difficult to observe and study using traditional techniques.

220 The short review of eye lens structure and development suggests that lens proteins are 221 promising hosts for the recovery of stable isotope life histories of marine animals, 
222 particularly for juvenile life stages. However, several additional factors currently limit the

223 use of lens protein as a useful target for the recovery of life history stable isotope records:

224

225 1. As lenses do not contain regular growth increments, age cannot be inferred directly

226 from the lens alone. Body length may potentially be inferred from lens diameter if

227 the relationship between lens diameter and body size is known. Body length then

228 may be related to age based on age:size relationships.

2292 2. Lens structure and specifically the hydration of lenses which may vary between

230 taxa. Sample preparation and handling protocols may therefore need to reflect

231 changes in lens composition and structure across taxa.

232 3. Lens proteins are composed of different proportional combinations of amino acids

233 to other commonly sampled tissues which could result in systematic offsets in

234 isotopic composition. The isotopic offset between lens proteins and muscle (or

235 other) tissues should be determined.

236 4. To improve confidence in a relatively new isotopic host tissue, recovery of expected

237 patterns of isotopic variance within and among individuals and species should be 238 demonstrated.

239

240 In the remainder of this study we address the points above using lens tissues from 241 elasmobranch and teleost fishes.

242

243 Materials and Methods 
244 Samples for this study were obtained opportunistically from research cruises and samples

245 available though other projects. Deep-water fishes often possess relatively large eyes for a

246 given body size, and consequently are attractive subjects for exploratory analyses of eye

247 lens chemistry. Lens and body measurements were obtained from two deep-water teleost

248 species, the black scabbardfish (Aphanopus carbo) and the roundnose grenadier

249 (Coryphaenoides rupestris), and two shallow water elasmobranch species, the porbeagle

250 shark (Lamna nasus) and spurdog (Squalus acanthias). A. carbo (n=19) and C. rupestris

$251(n=29)$ lenses were sampled from fish captured from deep-water trawl surveys off the west

252 Scotland continental slope in 2012 and 2013 onboard the MRV Scotia (survey methods

253 reported in Neat et al., 2010). Body measurements were recorded, and a randomly-chosen

254 sub-set of lenses from both species was processed for stable isotope analysis ( $\mathrm{n}=8$ and

$255 \mathrm{n}=11$, for $A$. carbo and C. rupestris, respectively).

256

257 Lamna nasus $(\mathrm{n}=30)$ lenses and associated body size data were collected from sharks 258 incidentally by-caught by off-shore commercial gill-net fisheries within the Celtic Sea 259 between 2011 and 2014, landed under dispensation in association with dedicated Cefas-led 260 scientific fishery studies (Bendall et al., 2012; Ellis et al., 2016). Lenses and allometric data 261 were recovered from Squalus acanthias (n=101) incidentally by-caught aboard inshore 262 commercial long line fisheries in the southern North Sea in 2013. A subset of 19 Squalus 263 acanthias individuals were randomly selected for isotopic investigation and white muscle 264 and lens samples extracted. A proportion of by-caught S. acanthias were pregnant females, 265 providing an opportunity to compare white muscle and lens tissues in a further 19 266 developing embryos. 
268 To compare lens morphology among species were obtained lenses from small numbers of 269 individuals form a range of taxa. Lenses were also extracted from cod (Gadus morhua, n=2), 270 haddock (Melanogrammus aeglefinus, $\mathrm{n}=4$ ), hake (Merluccius merluccius, $\mathrm{n}=4$ ) and conger 271 eels (Conger conger, $\mathrm{n}=2$ ) obtained from commercial fishermen operating in the English 272 Channel and North Atlantic. Monkfish (Lophius americanus) lenses $(n=6)$ were provided by

273 The School for Marine Science and Technology (SMAST), at the University of Massachusetts 274 (Dartmouth). Oceanic white-tip shark (Carcharhinus longimanus) lenses were obtained from 275 one by-caught specimen caught off Wallis and Futuna in the South Pacific, in 2012, whilst 276 blue shark (Prionace glauca) samples $(\mathrm{n}=2)$ were obtained from individuals caught by

277 Spanish and Portuguese long-lining vessels operating off the Canary Islands in 2014.

278 We recognize that sample sizes for morphological comparisons are extremely small, but the 279 aim was to compare lens structure among a range of fish taxa. We do not anticipate that 280 gross lens morphology and hydration is highly variable between individuals (and experience 281 sampling multiple individuals of the same species for isotopic analysis conform this) and so 282 we believe that the data collected provides a good indication of variability in lens structure 283 and permeability among the sampled taxa.

284

285 Tissue preparation

286 An incision was made along the length of the cornea of each fish, allowing the lens to be 287 removed using forceps. To test allometric relationships, the maximum diameter of the lens 288 was measured to the nearest $0.25 \mathrm{~mm}$ with calipers. Once excised, the lenses were frozen at 
$289-80^{\circ} \mathrm{C}$ overnight, before being freeze-dried for 12 hours. Once freeze-dried, lenses were 290 embedded in Epoxy resin (EpoFix) to secure the lenses for sectioning.

291

292 To compare lens core permeability between species, eye lenses extracted from a range of 293 teleost and elasmobranch species were freeze-dried and embedded in blue dyed Epoxy 294 resin. Penetration of the blue dye provides a relative measure of lens permeability to a 295 viscous, hydroscopic fluid after lyophilisation.

296

297 Embedded lenses were sectioned using two diamond wafering blades (0.3mm thick) 298 mounted upon a low-speed precision saw (Isomet-Buehler), separated by a $2 \mathrm{~mm}$ spacer. 299 The double blade system was used to produce a thin section, with one of the blades running 300 through the absolute core of the lens. This produced a section revealing the lens structure. 301 Dye-embedded lenses were also sectioned using the same instrument and settings, and the 302 resultant thin section imaged using a Panasonic Lumix FZ200 Bridge Camera.

303

304 Lenses were sampled for sequential analyses from 7 A. carbo, 11 L. nasus and 11 C rupestris 305 individuals. In preparation for stable isotope analysis, a second section was made across 306 the surface of the exposed lens produced by the first double-blade cut, producing a section 307 of lens, approximately $2 \mathrm{~mm}$ thick and $2 \mathrm{~mm}$ wide with the lens core at its center. The lens 308 strip was then sequentially sectioned by removing slivers of lens material, measuring 309 approximately $0.5 \mathrm{~mm}$ in width, using a scalpel. Sub-sampled segments of dried lens tissue 310 were weighed into tin capsules for stable isotope analysis. Samples of pure resin were also 311 submitted for analysis to monitor potential contamination. 
313 For $S$ acanthias, white muscle and lens samples were taken from 19 embryonic sharks.

314 Muscle samples were rinsed ten times in deionized water, to remove free ammonia, and 315 centrifuged for 10 minutes, before being rinsed a further ten times. Lens samples were 316 removed from the lens by physical peeling with no resin embedding. The muscle and lens 317 samples were frozen, lyophilized, and weighed prior to analysis.

\section{Analytical methods}

320 Stable carbon and nitrogen isotope ratios of teleost and L. nasus lens samples were

321 determined at OEA Laboratories Ltd. International reference material glutamic acid 322 (USGS40, Qi et al., 2003) were analyzed for every 10 unknown samples in each analytical 323 sequence. Isotope ratios are expressed in $\delta$ notation $\left(\%_{0}\right)$, relative to the international 324 standards of V-Pee dee belemnite and air for carbon and nitrogen, respectively. 325 Experimental precision for C. rupestris and L. nasus sample analysis was $0.21 \%$ for carbon 326 and $0.27 \%$ for nitrogen. Experimental precision for $A$. carbo sample analysis was $0.12 \%$ 327 and $0.16 \%$ or carbon and nitrogen, respectively (standard deviation of replicate USGS40 328 standards).

330 All $S$. acanthias lens and embryo muscle samples were analyzed at the NERC Life Sciences 331 Mass Spectrometry Facility (LSMSF) in East Kilbride, using a Pyrocube Elemental Analyzer 332 (2013, Elementar, Hanau, Germany) and Delta XP (Thermo Electron) mass spectrometer 333 (2003). Drift correction using a 3-point normalization was performed using three in-house 334 standards (GEL, ALAGEL and GLYGEL) encompassing a range of isotope compositions, run 
335 every ten samples, and a suite of GELs of different sizes were used to correct samples for

336 linearity (Werner and Brand 2001). GEL is a gelatin solution, ALAGEL an alanine-gelatine 337 solution, and GLYGEL a glycine-gelatine solution. Four differently sized USGS 40 glutamic

338 acid standards (Qi et al 2003, Coplen et al 2006) were used as independent checks of 339 accuracy and to acquire the calibration for $\mathrm{N}$ and $\mathrm{C}$ content. All data are reported with 340 respect to the international standard of AIR for $\delta^{15} \mathrm{~N}$ and V-PDB for $\delta^{13} \mathrm{C}$. Results are 341 reported in $\delta$ notation (McKinney et al. 1950). Experimental precision was $0.14 \%$ for 342 carbon and $0.13 \%$ for nitrogen (standard deviation of laboratory standard replicates).

343

344 To account for inter-laboratory variability, replicate glutamic acid standards from The 345 University of Southampton were analyzed at both facilities. Mean $\delta^{15} \mathrm{~N}$ and $\delta^{13} \mathrm{C}$ reported 346 for standards run at OEA Laboratories Ltd was $-3.99 \%( \pm 0.23)$ and $-12.99( \pm 0.27)$ 347 respectively, while the same standards run at the LSMSF facility returned mean $\delta^{15} \mathrm{~N}$ and $348 \delta^{13} \mathrm{C}$ values of $-3.84 \%( \pm 0.16)$ and $-13.03( \pm 0.24)$ respectively Therefore no inter349 laboratory corrections were applied.

350

\section{Results}

352 Allometric growth

353 The relationship between total length (TL, $\mathrm{mm}$ ) and lens diameter (LD, $\mathrm{mm}$ ) was linear 354 across the size range sampled (Figure 1). The best fit linear relationships between body 355 length and lens diameter are:

356

357 Aphonopus carbo LD $=-3.713( \pm 1.279)+0.0185( \pm 0.013) * \mathrm{TL}$ 
358 Coryphaenoides rupestris $\mathrm{LD}=-0.369( \pm 0.142)+0.0108( \pm 0.003) * \mathrm{TL}$

359 Lamna nasus $\mathrm{LD}=4.461( \pm 0.733)+0.0070( \pm 0.004) * \mathrm{TL}$

360 Squalus acanthias $\mathrm{LD}=0.479( \pm 0.181)+0.0109( \pm 0.002) * \mathrm{TL}$

363 In the case of $C$. rupestris and both shark species, a near-full size range of individuals was 364 sampled. C. rupestris specimens as small as $50 \mathrm{~mm}$ were obtained, representing the early 365 juvenile life history stage of this species. Similarly, a juvenile L. nasus measuring $1130 \mathrm{~mm}$ 366 was captured (size at birth is estimated at $\sim 800-900 \mathrm{~mm}$ (Ebert et al. 2013.)). We also sampled developing Squalus acanthias embryos, thus we are confident that the allometric growth equations (eq. 2-4) accurately reflect the relationship between lens diameter and body size for S. acanthias. An analysis of covariance (ANCOVA) revealed that lens diameter is influenced by individual size (TL) and species $\left(\mathrm{F}_{1,189}=9275.18, \mathrm{p}=<0.001\right.$ and $\mathrm{F}_{3,189}=$

$371264, \mathrm{P}=<0.001$, respectively $)$ as the interaction of these variables $\left(\mathrm{F}_{3,189}=38.79, \mathrm{p}=\right.$ $372<0.001)$. Thus, the slopes and intercepts of equations 1-4 differ from one another, and the 373 allometric relationship between body size and lens diameter differs between species.

375 Comparison of lens morphology and permeability

376 Sectioned teleost lenses reveal well-defined, concentric banding, which is enhanced during 377 freeze-drying as weaknesses between fiber cell layers promote concentric fractures (Figure 378 2). Assuming that within-species variation in lens structure is minimal, distinct differences 379 in lens morphology and the structural response of the lens to freeze-drying are seen 380 between species: G. morhua, C. conger, and L. americanus lenses all have clear, concentric 
381 bands throughout, radiating from the lens core to edge (outer cortex). M. merluccius, $M$.

382 aeglefinus, and $A$. carbo lenses also display clear concentric banding throughout the solid 383 core region of the lens, but with no clear structure within the hydrated outer cortex region.

384 M. merluccius, M. aeglefinus, and A. carbo lenses were relatively hydrated compared to $G$.

385 morhua and $C$. conger lenses, and required careful handling to avoid puncturing the lens 386 membrane, which would result in the loss of the gelatinous material.

387

388 All elasmobranch lenses included in this comparison presented difficulties associated with 389 handling prior to freeze-drying, due to the large proportion of gelatinous material.

390 The core region of all elasmobranch lenses examined here was generally less dense than 391 that of the teleosts. Sampled elasmobranch lenses also show less concentric banding, and 392 increased hydration relative to teleost lenses (Figure 2). The relative penetration of dyed 393 resin into the lens differs according to the species examined. For example, the lenses of $G$. 394 morhua, C. conger, and M. merluccius are relatively impermeable, (Figure 2). Conversely, in 395 lenses of L. nasus, C. longimanus, M. aeglefinus, and L. americanus, resin penetrated to the 396 core of the lens, possibly via fractures produced during freeze-drying. A qualitative ranking 397 of susceptibility to resin contamination was (most susceptible first): P. glauca $>$ L. nasus > 398 L. americanus $>$ M. aeglefinus $>$ S. acanthias $>$ A. carbo $>$ C. longimanus $>$ M. merlucuius $>$ C. 400 of more hydrated lenses during freeze drying and / or variations in lens porosity. 401 402 Stable isotope data 
403 Penetration of stained resin into the lens (figure 2) indicates the potential for

404 contamination of lens protein with carbon and nitrogen derived from the resin. The 405 isotopic composition of pure resin differs markedly from that of lens protein, allowing us to 406 use a simple mass balance approach to estimate the relative proportion of resin in each 407 sub-sample:

408

409

$\delta^{13} C_{s}=A * \delta^{13} C_{r}+B * \delta^{13} C_{l}$

410 where $\delta^{13} C_{s}$ represents the isotopic composition of the potentially mixed sample (i.e. lens 411 and resin), $\delta^{13} C_{r}$ represents the isotopic composition of carbon in the pure resin $(-29.5 \%)$ 412 and $\delta^{13} \mathrm{C}_{\mathrm{l}}$ represents the isotopic composition of carbon in a pure lens sample (estimated 413 from core values for each species), and A and B represent the relative proportion of resin 414 and lens in each sample, respectively. As equation (5) represents a two-component mass 415 balance, it can be solved explicitly to yield the proportional contributions of resin-derived 416 carbon in any mixed sample given isotopic compositions for $\delta^{13} \mathrm{C}_{\mathrm{s}}, \quad \delta^{13} \mathrm{C}_{\mathrm{r}}$ and $\delta^{13} \mathrm{C}_{\mathrm{l}}$. The 417 equation above assumes that core and edge $\delta^{13} \mathrm{C}$ values do not differ significantly compared 418 to the isotopic difference between resin and lens protein, this is most likely met where the 419 isotopic composition of the resin is relatively low (as here), but the relative $\delta^{13} \mathrm{C}$ values 420 between lens and resin should be noted prior to any assessment of contamination. We 421 cannot apply similar mass balance approaches with $\delta^{15} \mathrm{~N}$ values, as we expect core and 422 edge $\delta^{15} \mathrm{~N}$ values to vary systematically (but to an uncertain degree) with body size and 423 trophic level. 
425 Isotope data suggest that resin contamination occurred and penetrated through to the core

426 in all lenses (Table 1). If the proportion of resin estimated in a given sample exceeded $20 \%$,

427 that sample was excluded from any further analyses to avoid excessive errors associated

428 with large corrections. Where the percentage of resin within a particular sample was less

429 than this threshold $(<20 \%)$, the degree of contamination was corrected for using the 430 following equation:

431

432

$\delta^{13} C_{C}=\frac{\left(\delta^{13} C_{s} * C N_{s}\right)-\left(\delta^{13} C_{r} *\left(C N_{s}-3.7\right)\right.}{3.7}$

433

434 where $\delta{ }^{13} \mathrm{C}_{\mathrm{c}}$ represents the corrected isotopic composition of a given sample, and 435 subscript "s" and " $r$ " denote uncorrected carbon isotope composition of the sample, and 436 pure resin, respectively. 3.7 reflects the C:N ratio of a pure protein). Lenses of $C$. rupestris 437 were most susceptible to resin contamination with $39 \%$ of all samples containing $>20 \%$ 438 resin, followed by L. nasus with $36 \%$ of samples exceeding $20 \%$ contamination. Relatively 439 little resin contamination was observed in $A$. carbo lenses, and only $13 \%$ of these samples 440 were omitted from the dataset due to contamination.

442 Ontogenetic trends in stable isotope compositions across lenses

444 Symmetrical ontogenetic trends in resin-corrected $\delta^{15} \mathrm{~N}$ and resin-corrected $\delta^{13} \mathrm{C}$ values 445 centered around the lens core were recovered for all sampled Aphanopus carbo lenses. The 446 total length of the fish associated with each lens sub-sample was estimated using equation 
447 (1) and the corresponding distance from lens core (mm). In general, $\delta^{15} \mathrm{~N}$ and $\delta^{13} \mathrm{C}$ values

448 increase with body size in $A$. carbo with a sharp isotopic excursion associated with the lens 449 core (Figure 3).

450

451

Among-species comparisons of lens isotope compositions

452

453 Among-species comparisons in the isotopic composition of eye lens proteins were carried

454 out between C. rupestris, L. nasus and A. carbo. Due to the high resin content of sequential 455 lens samples of C. rupestris and L. nasus, only isotope values from the lens core, 456 representing early juvenile compositions, are compared among species. The isotopic 457 compositions of the lens core of the three sampled species are distinct (Figure 4) (one-way 458 ANOVA, $\mathrm{F}=8.01, \mathrm{df}=2, \mathrm{p}=0.001$, and $\mathrm{F}=44.13, \mathrm{df}=2, \mathrm{p}=<0.001$, for carbon and nitrogen, 459 respectively). Lowest mean nitrogen isotope ratios are seen in $C$. rupestris (mean $=7.95 \%_{0}$ $460 \pm 1.68)$, followed by $A$. carbo (mean $\left.=11.58 \%_{0} \pm 1.23\right)$ and $L$. nasus $\left(\right.$ mean $=15.22 \%_{0} \pm$ 461 1.81). Lens core carbon isotope compositions for C. rupestris and L. nasus are distinct from 462 one another, however there is considerable isotopic overlap between $A$. carbo, and both $C$. 463 rupestris and L. nasus.

464

465

Isotopic fractionation between lens and muscle tissue

466 The isotopic composition of lens and muscle samples from 19 S. acanthias embryos was 467 compared. Lens and muscle tissue formed in utero are derived from the same nutrient 468 source (egg yolk) and have similar isotopic incorporation times, not exceeding the species' 469 gestation period. Due to the small size of pup lens samples, whole lenses were analyzed. A 
470 lipid correction model based on S. acanthias (Reum, 2011) was applied to the muscle data.

471 The isotopic compositions of lens protein from $S$. acanthias show similar variability in both

$472 \delta^{15} \mathrm{~N}$ and $\delta^{13} \mathrm{C}$ values compared to muscle (Figure 5, Levene's test of homogeneity of

473 variances $\mathrm{F}$ value $=0.48$ in both cases, $\mathrm{p}>0.45$ ). Muscle tissue was enriched in both ${ }^{13} \mathrm{C}$ and

$474{ }^{15} \mathrm{~N}$ relative to lens protein (paired t-test, mean offset in carbon, $=0.66 \pm 0.22 \%, \mathrm{t}=12.55$,

475 degrees of freedom $=18, p=<0.001$ : mean offset in nitrogen $=0.66 \pm 0.36 \% t=7.56$, degrees

476 of freedom $=18, \mathrm{p}=<0.001$.

477

478 Finally, $\delta^{15} \mathrm{~N}$ and $\delta^{13} \mathrm{C}$ values from the lens core of mature $C$. rupestris $(\mathrm{n}=11)$ were 479 compared with existing measurements of $\delta^{15} \mathrm{~N}$ and $\delta^{13} \mathrm{C}$ values of muscle tissue from early 480 juvenile $C$. rupestris specimens measuring $\leq 50 \mathrm{~mm}$, recovered from the same region $(n=5)$. 481 Lens tissues displayed a greater range in both $\delta^{15} \mathrm{~N}$ and $\delta^{13} \mathrm{C}$ values compared to muscle 482 (Figure 6), but variances were not significantly different (Levene's test of homogeneity of 483 variances $\mathrm{F}$ value $=1.4\left(\delta^{13} \mathrm{C}\right)$ and $1.8\left(\delta^{15} \mathrm{~N}\right)$, in both cases, $\left.\mathrm{p}>0.15\right)$. Lenses were again 484 generally depleted in ${ }^{13} \mathrm{C}$ and ${ }^{15} \mathrm{~N}$, but mean $\delta^{15} \mathrm{~N}$ and $\delta^{13} \mathrm{C}$ values did not differ significantly 485 between lens and muscle proteins $\left(\delta^{15} \mathrm{~N}-\mathrm{t}=0.495, \mathrm{p}=0.332, \delta^{13} \mathrm{C}-\mathrm{t}=-1.001, \mathrm{p}=0.332\right)$. 486 487

\section{Discussion}

488 We initially identified the following issues that need to be addressed before eye lens tissues 489 can be used as an effective target for ontogenetic stable isotope analyses:

(1) The relationship between lens diameter and body size should be tested across taxa. 
492

494 495

496

497 individuals should be demonstrated across a range of taxa.

498

499

500

501

502

503

504 505

506

507 50 509 510 species, at least until sufficient species have been assessed to develop predictive 511 relationships.

512

513

(2) The structure of lenses should be compared between taxa, and a consistent sampling methodology should be determined.

(3) The isotopic offset between lens and muscle tissue should be calculated across taxa.

In addition, we suggested that isotopic differences expected between and within Below we address each of these issues in turn.

\section{(1) Allometry}

Lens accretion occurs in linear proportion to somatic growth in each of the four species studied in detail (A. carbo, C. rupestris, L. nasus and S. acanthias). Linear allometry between lens radius and body size indicates that the lens presents a near whole-life chronology of chemical information with greater temporal resolution during periods of rapid body size growth. Allometric growth allows retrospective estimation of the approximate size of the fish corresponding to a particular location within the lens. The slope and intercepts of the lens to body size (and therefore potentially lens diameter to age) relationship differ between species, requiring allometric relationships to be estimated for each new study

(2) Lens structure and sampling methodology 
514 Fish eye lenses are relatively difficult tissues to handle due to their partially hydrated, 515 gelatinous exterior, hard internal core and spherical shape. Two alternative sampling 516 processes have been proposed: peeling layers from the lens, developed by Parry (2003) 517 and later applied by Wallace et al. (2014), and embedding and sectioning comparable to 518 more standard sclerochronological sampling methods. The peeling technique represents a 519 simple and attractive method to sample eye lenses, but sequential peeling techniques are 520 difficult to apply where lenses are either highly crystalline or highly gelatinous. 521 Additionally, it is relatively difficult to accurately control the depth of each sequential layer 522 peeled from a lens, making cross-referencing to age models inaccurate. Embedding lenses 523 in a resin medium then sectioning could provide a more reliable sampling technique, but 524 embedding methods bring the tissue into contact with a potential contaminant (the resin 525 embedding medium) and permeability of the lens to the embedding medium is therefore a 526 critical concern. We found high interspecific diversity in permeability to epoxy resin among 527 lenses (Figure 2), however teleost lenses are generally denser and less hydrated relative to 528 those of elasmobranchs. The extent of contamination as assessed by carbon isotope mass 529 balance was also highly variable between species, ranging from $<10 \%$ for dense lenses of $A$. 530 carbo, and core regions in other species, to more than $30 \%$ in the hydrated outer portions 531 of Lamna nasus and Coryphaenoides rupestris lenses. Visual assessment of resin 532 contamination similarly suggested that the susceptibility to contamination corresponds to 533 the degree of hydration of the lens, and freeze-drying appears to enhance resin 534 contamination during embedding, possibly because of the development of fractures that 535 penetrate circumferential lamellae. The degree of hydration ultimately influences the 536 ability to sample lenses accurately and precisely via both peeling and sectioning. 
538 Lens size may be a driving factor of the relative hydration of lenses and, consequently, the

539 suitability of a particular lens to resin embedding and sectioning. For example, blue shark,

540 oceanic whitetip shark, haddock and black scabbardfish lenses are both the largest lenses

541 and the most hydrated (a priori observations). Increased porosity or hydration in large

542 lenses may be associated with the demand for lenses to remain transparent and reduce

543 light refraction. With increasing size comes an increase in the path length that light must

544 travel through the lens, which in turn increases the potential for light scattering. Maximum

545 protein concentration may thus be limited in larger lenses to a lower level than that of 546 smaller lenses (Kroger, 2013) in order to reduce light scattering. The structure of a

547 particular lens will ultimately determine the methodology used, and each species must be 548 addressed on a case-by-case basis. The "peeling" technique (Parry 2003; Wallace et al., 549 2014) represents a high-resolution, contamination-free technique, and should be the first 550 choice method. Where "peeling" is not possible, or where accurately resolved distances 551 across the lens are required, the resin-embedding method provides an alternative 552 approach, but only for relatively dense lenses, and the potential for contamination must be 553 assessed. In the case of highly gelatinous lenses, neither methodology discussed in this 554 paper is suitable, at least for recovering sequential samples across the lens.

557 (3) Potential for isotopic offset between lens and muscle protein

558 Estimates of isotopic fractionation between tissues are generally performed across tissues 559 in the same individual. This methodology is relatively difficult for eye lens proteins as (a) 
560 integration times for muscle and lens protein are unknown and (b) outer portions of lenses

561 are hydrated, gelatinous and difficult to sample accurately. We therefore took two

562 complementary approaches: comparisons of lens and muscle tissues within developing

563 embryos, and comparing lens and muscle between different individuals but at similar life

564 stages.

565

566 Tissues of oviparous embryonic sharks form over relatively similar timescales, are 567 sustained from a single, isotopically constant yolk sac nutrient source, and have no isotopic 568 memory associated with tissue turnover. Embryonic oviparous sharks therefore provide a 569 uniquely constrained opportunity to determine potential isotopic offset effects associated 570 with tissue compositions. Within individual embryos of $S$. acanthias, lens protein was

571 significantly lower in both $\delta^{15} \mathrm{~N}$ and $\delta^{13} \mathrm{C}$ values compared to muscle protein (mean 572 difference $=0.66 \pm 0.36 \%_{0}, \mathrm{p}=<0.01$, and $0.66 \pm 0.23 \% \%_{0}, \mathrm{p}=<0.01$, for nitrogen and carbon, 573 respectively).

574

575 For teleosts, we compared lens protein values in the core regions from adult fish with those 576 of juvenile fish of equivalent sizes (calculated from allometric relationships); we therefore 577 compare across individuals from different year classes, but of equivalent size (Figure 6). 578 Mean $\delta^{13} \mathrm{C}$ and $\delta^{15} \mathrm{~N}$ values in eye lens proteins were again lower relative to muscle tissue 579 from Coryphaenoides rupestris specimens, however the absolute offset is small and 580 effectively obscured by the additional variance associated with un-matched individuals. 581 Consequently, lens protein appears to be lower in both nitrogen and carbon isotope values 582 compared to muscle protein for both elasmobranchs and teleosts, but the isotopic 
583 differences are less than $0.75 \%_{0}$ and $0.25 \%{ }_{0}$ for $\delta^{15} \mathrm{~N}$ and $\delta^{13} \mathrm{C}$ respectively, and likely to be

584 obscured by between-individual variation and analytical error.

585

586 (4) Recovery of expected isotopic differences within and between species

587 Transects of $\delta^{15} \mathrm{~N}$ and $\delta^{13} \mathrm{C}$ values across whole lenses of Aphanopus carbo show a high

588 degree of bilateral symmetry, i.e. different locations of roughly equal radial distance from

589 the core record similar isotopic compositions. All A. carbo specimens analyzed in this study

590 show progressive enrichment in $\delta^{15} \mathrm{~N}$ values consistent with a priori expectations of

591 increasing trophic level with body size in this species (Trueman et al., 2014), and agree

592 with published trends in the lens nitrogen isotope values of teleosts (Wallace, 2014). The

593 one exception is the presence of elevated core $\delta^{15} \mathrm{~N}$ value in one $A$. carbo specimen (M113,

594 Figure 2(a)). We attribute this to the presence of a maternal signal at the absolute core,

595 which may elevate the $\delta^{15} \mathrm{~N}$ value of this sample relative to adjacent tissue. Similar

596 anomalous chemical compositions associated with maternal contributions or larval

597 developmental physiology have been noted in otolith core regions (e.g. Ben-Tzvi et al., 598 2007).

599

$600 \delta^{15} \mathrm{~N}$ and $\delta^{13} \mathrm{C}$ ratios in the lens core differed significantly between the three sampled 601 species (Figure 4). $\delta^{15} \mathrm{~N}$ values increase from the zooplanktivorous C. rupestris to the

602 piscivorous A. carbo and are highest in the viviparous L. nasus, consistent with expected 603 relative trophic levels for early juveniles of these species. A. carbo and C. rupestris 604 specimens were both sampled from the north east Atlantic continental slope west of 605 Scotland, but genetic and microchemical data indicate that $C$. rupestris is a lifelong resident 
606 species, while A. carbo individuals spend their earliest life stages in southern waters

607 around Madeira (Longmore et al., 2014). $\delta^{13} \mathrm{C}$ values successfully distinguish the resident $C$.

608 rupestris from the migratory A. carbo. Between-species variation in the isotopic

609 composition of lens core protein is thus greater than among-individual variation, as

610 expected for these functionally distinct species.

611

612

613 Additional complexities associated with lens-based methodologies

614 The data presented above, together with previous published studies, clearly demonstrate

615 that eye lenses of teleosts and elasmobranchs can provide retrospective, whole life records

616 of isotopic compositions, which can be compared to isotopic data recovered from

617 alternative tissues. These life history records can be exploited to study spatial and trophic

618 ecology, particularly relating to early juvenile life stages.

620 The application of lens-based methodologies to investigate chondrichthyan ecology is

621 additionally complicated by the varied reproductive strategies adopted by members of this

622 class. Sharks, rays and skates expend a large amount of energy producing relatively few,

623 well developed offspring, via oviparous or viviparous (placental/aplacental) strategies.

624 Embryos are maternally nourished either directly (vivipary) or indirectly via the yolk sac

625 (oviparity/aplacental vivipary), thus the chemical composition of tissue formed during

626 embryonic development reflects the diet of the pregnant mother. While this provides a

627 potentially exciting opportunity to study the movements of pregnant females via analysis of

628 lens core chemistry, there are several factors that must first be addressed. The duration of 
629 maternal nourishment varies considerably between species, with gestation ranging from

630 months to years, thus the relative proportion of the lens representative of maternal

631 nourishment varies according to species, an estimate of which is required in order to

632 isolate lens tissue formed pre-birth from that representative of exogenous feeding in the

633 juvenile life history stage. Where size-at-birth data are available, this information can be

634 used alongside the growth relationship parameters in order to isolate lens tissue formed

635 pre-birth from lens tissue accreted post-parturition.

636

637 In viviparous species, isotopic variability within the pre-birth portion of the lens is likely to 638 reflect changes in diet and/or location of the gestating female. However, in oviparous and 639 aplacental viviparous species, the pre-birth lens tissue reflects maternal nutrient 640 assimilation during egg sac formation. Given that yolk capsules may be laid down prior to 641 the initiation of embryo growth (Wood et al., 1979), there is potential for considerable 642 temporal decoupling between maternal feeding fuelling yolk sac production, and the 643 subsequent utilization and incorporation of this material into the tissues of the embryo. 644 Furthermore, in aplacental viviparous species, the potential for pre-birth omnivory in the 645 developing embryo presents an additional complication. Consumption of unfertilized eggs 646 (oophagy) formed at different times may further complicate the issue of temporal 647 decoupling, whilst consumption of un-hatched embryos (embryophagy) could introduce an 648 additional trophic offset, similar to that associated with maternal partitioning. 649 650 Conclusions 651 
652 Many researchers have exploited incrementally grown tissues in fishes for aging studies,

653 investigations into stock discrimination, and isotope ecology. Here we show that eye lens

654 tissue also serves as a repository for stable isotope-derived information relating to the

655 whole life-history of an individual, allowing retrospective investigation of trophic history

656 and habitat use in both teleosts and chondrichthyans. Stable isotope analyses of fish eye

657 lenses can provide information on movements and trophic dynamics of otherwise

658 inaccessible species. The structure and mechanical properties of the fish lens differs

659 markedly between species, however, and can present problems associated with handling. It

660 is therefore important to assess lens morphology on a case-by-case basis, and to develop

661 handling and preparation protocols that can be adapted accordingly to suit different

662 species. Lenses are relatively porous materials, susceptible to contamination by resin-

663 based embedding media. There may be scope for further testing of different embedding

664 media with preferably lower permeability, or solvent-based approaches for removing resin

665 from cut sections. In the meantime, we suggest that chemical-free handling protocols such

666 as 'peeling' the lens are preferable, despite a reduction in control over the sampling

667 interval and associated uncertainty in the time represented by each sample. Further

668 research is also required in order to reliably interpret isotopic compositions of lens tissue

669 formed in utero in elasmobranchs, or in other viviparous fishes. Sharks, rays and skates

670 require special attention, and given the range of reproductive strategies, the associated

671 maternal nourishment, and the variable gestation period, each species should be addressed 672 on a case-by-case basis.

673 
674 In conclusion, the eye lens represents a promising target for biochemical reconstruction of 675 life-long diet and spatial ecology in fishes, but interpretation of lens isotope data, 676 particularly in the pre-birth portion of the lens, requires care and detailed consideration of 677 the relative timescales associated with tissue formation.

678

\section{Acknowledgements}

680

681 The authors would like to extend thanks to Crista Bank (The School for Marine Science and 682 Technology, at the University of Massachusetts) and staff at Cefas (Lowestoft) for providing 683 samples. We thank Jason West, Orian Tzadik and an anonymous reviewer for helpful and 684 constructive comments on the manuscript.

685

686

\section{Figure Captions}

687

Figure 1 - The relationship between total length (TL) and lens diameter (LD) for (a) the 689 black scabbard fish, Aphanopus carbo, $\left(\mathrm{n}=19, \mathrm{r}^{2}=0.917, \mathrm{p}=<0.001\right)$, (b) the roundnose 690 grenadier, Coryphaenoides rupestris, $\left(n=29, r^{2}=0.973, p=<0.001\right)$, (c) the porbeagle

691 shark, Lamna nasus ( $\left.\mathrm{n}=30, \mathrm{r}^{2}=0.901, \mathrm{p}=<0.001\right)$, and (d) the spurdog, Squalus acanthias 692 $\left(\mathrm{n}=101, \mathrm{r}^{2}=0.959, \mathrm{p}=<0.001\right)$

693

694 Figure 2 - Thin sections of teleost and elasmobranch lenses embedded in pigmented Epoxy 695 resin. (A) black scabbardfish (Aphanopus carbo). (B) monkfish (Lophius americanus). (C) 696 cod (Gadus morhua). (D) conger eel (Conger conger). (E) hake (Merluccius merluccius). (F) 
697 haddock (Melanogrammus aeglefinus). (G) porbeagle (Lamna nasus). (H) spurdog (Squalus

698 acanthias). (I) blue shark (Prionace glauca). (J) oceanic white-tip shark (Carcharhinus 699 longimanus). White lines are $5 \mathrm{~mm}$ scale bars.

700

701 Figure 3 - Bivariate plots of $\delta{ }^{15} \mathrm{~N}$ (blue) and $\delta{ }^{13} \mathrm{C}$ (red) variability through Aphanopus 702 carbo lenses. The corresponding estimate of individual fish total length at time of tissue 703 formation was recovered from relationship shown in Figure 1(A), and the location of the 704 sample from the lens transect.

705

706 Figure 4 - Comparison of lens core $\delta{ }^{13} \mathrm{C}$ and $\delta{ }^{15} \mathrm{~N}$ values for Coryphanoides rupestris, 707 Aphanopus carbo and Lamna nasus. Error bars show standard deviation.

708

709 Figure 5 - Comparison of lens and muscle $\delta{ }^{15} \mathrm{~N}$ and $\delta{ }^{13} \mathrm{C}$ values from 19 Squalus 710 acanthias embryos.

711

712 Figure 6 - Comparison of lens core and muscle $\delta{ }^{15} \mathrm{~N}$ and $\delta{ }^{13} \mathrm{C}$ values from Coryphaenoides 713 rupestris specimens measuring $\leq 50 \mathrm{~mm}$. Eye lenses and muscle samples were obtained 714 from specimens caught during the deep-water survey onboard MRV Scotia; lenses were 715 excised from fish caught in September 2012, and the muscle originates from specimens 716 caught during September 2013.

\section{References}


719 Augusteyn, R. C. 2010. On the growth and internal structure of the human lens.

720 Experimental eye research. 90: 643-654. Available from:

721 http://www.pubmedcentral.nih.gov/articlerender.fcgi?artid=2871961\&tool=pmcentr

722 ez\&rendertype=abstract (Accessed 25 August 2014).

723 Ball, L. E., Garland, D. L., Crouch, R. K. and Schey, K. L. 2004. Post-translational modifications

724 of aquaporin 0 (AQP0) in the normal human lens: spatial and temporal occurrence.

725 Biochemistry. 43: 9856-9865.

726 Bassnett, S. and Beebe, D. C. 1992. Coincident loss of mitochondria and nuclei during lens

727 fiber cell differentiation. Developmental dynamics: an official publication of the $728 \quad$ American Association of Anatomists. 194: 85-93.

729 Bassnett, S. 2002. Lens organelle degradation. Experimental eye research. 74: 1-6.

730 Bendall, V.A., Hetherington, S.J., Ellis, J.R., Smith, S.F., Ives, M.J., Gregson, J. and Riley, 731 A.A.(2012). Spurdog, porbeagle and common skate bycatch and discard reduction.

732 Fisheries Science Partnership 2011-2012, Final report, 88 pp.

733 Ben-Tzvi, O., Abelson, A., Gaines, S.D., Sheehy, M.S., Paradis, G.L. and Miflawi, M. 2007. The 734 inclusion of sub-detection limit LA-ICPMS data, in the analysis of otolith 735 microchemistry, by use of a palindrome sequence analysis (PaSA). Limnology and 736 Oceanography: Methods 5, 97-105

737 Best, P. B. and Schell, D. M. 1996. Stable isotopes in southern right whale (Eubalaena 738 australis) baleen as indicators of seasonal movements, feeding and growth. Marine 739 Biology. 124: 483-494.

740 Bird, C.S., Veríssimo, A., Magozzi, S., Abrantes, K.G., Aguilar, A., Al-Reasi, H., Barnett, D.M., 741 Bethea, A., Biais, G., Borrell, A., Bouchoucha, M., Boyle, M., Brooks, E.J., Brunnschweiler, 
742

743

744

745

746

747

748

749

750

751

752

753

754

755

756

757

758

759

760

761

762

763

764

J., Bustamante, P., Carlisle, A., Catarino, D., Caut, S., Cherel, Y., Chouvelon, T., Churchill, D., Ciancio, J., Claes, J., Colaço, A., Courtney, D., Cresson, P., Daly, R., de Necker, L., Endo, T., Figueiredo, I., Frisch, A.J., Hansen, J.H., Heithaus, M., Hussey, N.E., Iitembu, J., Juanes, F., Kinney, M.J., Kiszka, J.J., Klarian, S.A., Kopp, D., Leaf, R., Li, Y., Lorrain, A., Madigan, D., Maljković, A., Malpica-Cruz, L., Matich, P., Meekan, M., Menard, F., Menezes, G.M., Munroe, S., Newman, M., Papastamatiou, Y., Pethybridge, H., Plumlee, J.D., Polo-Silva, C., Quaeck-Davies, K., Raoult, V., Reum, J., Torres-Rojas, Y.E., Shiffman, D.S., Shipley, O.N., Speed, C.W., Staudinger, M., Teffer, A., Tilley, A., Valls, M., J.J., Wai, T-C., Wells, R.J.D., Wyatt, A.S.J., Yool, A and Trueman, C.N. 2018. A global perspective on the trophic geography of sharks. Nature Ecology and Evolution 2, 299-305. doi: 10.1038/s41559017-0432-z

Bloemendal, H., de Jong, W., Jaenicke, R., Lubsen, N. H., Slingsby, C. and Tardieu, A. 2004. Ageing and vision: structure, stability and function of lens crystallins. Progress in biophysics and molecular biology. 86: 407-485.

Blundell, T., Lindley, P., Miller, L., Moss, D., Slinsby, C., Tickle, I., Turnell, B., and Wistow, G. 1981. The molecular structure and stability of the eye lens: X-ray analysis of $\gamma$ crystallin II. Nature. 289: 771-777.

de Busserolles, F., Fitzpatrick, J. L., Paxton, J. R., Marshall, N. J. and Collin, S. P. 2013. Eye-size variability in deep-sea lanternfishes (myctophidae): an ecological and phylogenetic study. PloS ONE, 8: 1-14.

Bron, A.J., Vrensen, G.F.J.M., Koretz, J.F., Mariani, G. and Harding, J.J. 2000. The ageing lens. Opthalmologica 214: 86-104

Cailliet, G. M. and Goldman, K. J. 2004. Age determination and validation in chondrichthyan 
fishes. In. Carrier, J. C., Musick, J. A. and Heithaus, M. R. (Eds.) Biology of sharks and their relatives (pp. 399-448). Boca Raton: CRC Press.

767 Campana, S. E. 1999. Chemistry and composition of fish otoliths: pathways, mechanisms and applications. Marine Ecology Progress Series. 188: 263-297.

769 Cherel, Y., Kernaleguen, L., Richard, P. and Guinet, C. 2009. Whisker isotopic signature 770 depicts migration patterns and multi-year intra- and inter-individual foraging 771 strategies in fur seals. Biology Letters. 5: 830-832.

772 Coplen, T. B., Brand, W. A., Gehre, M., Gröning, M., Meijer, H. A. J., Toman, B., and

773 Verkouteren, R. M., 2006, New guidelines for $\delta 13 \mathrm{C}$ measurements Analytical Chemistry 78, 2439-2441.

775

776

Dove, S. G. and Kingsford, M. J. 1998. Use of otoliths and eye lenses for measuring trace-

777

778

779

780

781

782

783

784

785

786

787 metal incorporation in fishes: a biogeographic study. Marine Biology. 130: 377-387.

Ebert, D. A., Fowler, S., Compagno, L. 2013. Sharks of the World - A Fully Illustrated Guide. Wild Nature Press.

Ellis, J. R., Bendall, V. A., Hetherington, S. J., Silva, J. F. and McCully Phillips, S. R. (2016). National Evaluation of Populations of Threatened and Uncertain Elasmobranchs (NEPTUNE). Project Report (Cefas), $\mathrm{x}+105 \mathrm{pp}$.

Estrada, J.A., Rice, A.N., Natanson, L.J. and Skomal, G.B. 2006. Use of isotopic analysis of vertebrae in reconstructing ontogenetic feeding ecology in whaite sharks. Ecology 87: 829-834.

Gillanders, B. M. 2001. Trace metals in four structures of fish and their use for estimates of stock structure. Fisheries Bulletin. 99: 410-419. 
determination. Trends in Genetics. 8: 349-355.

789 Grønkjær, P., Pedersen, J. B., Ankjærø, T. T., Kjeldsen, H., Heinemeier, J., Steingrund, P., 790 Nielsen, J. M. and Christiensen, J. T. 2013. Stable N and C isotopes in the organic matrix 791 of fish otoliths: validation of a new approach for studying spatial and temporal 792 changes in the trophic structure of aquatic ecosystems. Canadian Journal of Fisheries 793 and Aquatic Sciences. 70: 143-146.

794 Gutierrez, D. B., Garland, D. and Schey, K. L. 2011. Spatial analysis of human lens aquaporin795 0 post-translational modifications by MALDI mass spectrometry tissue profiling. Experimental eye research. 93: 912-20.

797 Hamlett, W. C., Eulitt, A. M., Jarrell, R. L. and Kelly, M. A. 1993. Uterogestation and 798 placentation in elasmobranchs. Journal of Experimental Zoology 266, 347-367.

799

Hanson, N.N., Wurster, C.M., EIMF and Todd, C.D. 2010. Comparison of secondary ion mass

800

801

802 spectrometry and micromilling/continusous flow isotope ratio mass spectrometry

\section{3}

804

Hedfalk, K., Törnroth-Horsefield, S., Nyblom, M., Johanson, U., Kjellbom, P. and Neutze, R. 805 2006. Aquaporin gating. Current opinion in structural biology. 16: 447-56.

Hobson, K. A. and Schell, D. M. 1998. Stable carbon and nitrogen isotope patterns in baleen 806 from eastern Arctic bowhead whales (Balaena mysticetus). Canadian Journal of 807 Fisheries and Aquatic Sciences. 55: 2601-2607.

Høie, H., Otterlei, E. and Folkvord, A. 2004. Temperature-dependant fractionation of stable 809 oxygen isotopes in juvenile cod (Gadus morhua L.). ICES Journal of Marine Science. 61: 243-251. 
811 Hunsicker, M. E., Essington, T. E., Aydin, K. Y. and Ishida, B. 2010. Predatory role of the

812 commander squid Berryteuthis magister in the eastern Bering Sea: insights from stable 813 isotopes and food habits. Marine Ecology Progress Series. 415: 91-108.

814 Kalish, J. M. 1991. ${ }^{13} \mathrm{C}$ and ${ }^{18} \mathrm{O}$ isotopic disequilibria in fish otoliths: metabolic and kinetic 815 effects. Marine Ecology Progress Series. 75: 191-203.

816 Kim, S. L., Tinker, M. T., Estes, J. A. and Kock, P. L. 2012. Ontogenetic and Among-Individuals 817 Variation in Foraging Strategies of Northeast Pacific White Sharks Based on Stable $818 \quad$ Isotope Analysis. PLoS ONE. 7(9): 1-11.

819 Kingsford, M. J. and Gillanders, B. M. 2000. Variation in concentrations of trace elements in 820 otoliths and eye lenses of a temperate reef fish, Parma microlepis, as a function of 821 depth, spation scale, and age. Marine Biology. 137: 403-414.

822 Kjeldsen, H., Heinmeier, J., Heegaard, S., Jacobsen, C. and Lynnerup, N. 2010. Dating the time 823 of birth: A radiocarbon calibration curve of human eye-lens crystallines. Nuclear $824 \quad$ Instruments and Methods in Physics Research B, 268: 1303-1306.

825 Kröger, R.H.H., 2013. Optical plasticity in fish lenses. Progress in Retinal and Eye Research, $826 \quad 34: 78-88$

827 Lee, S. H., Schell, D. M., McDonald, T. L. and Richardson, W. J. 2005. Regional and seasonal 828 feeding by bowhead whales Balaena mysticetus as indicated by stable isotope ratios. 829 Marine Ecology Progress Series. 285: 271-287.

830 Longmore, C., Trueman, C. N., Neat, F., O’Gorman, E. J., Milton, J. A. and Mariani, S. 2011. 831 Otolith geochemstry indicates life-long spatial population structuring in a deep-sea 832 fish, Coryphaenoides rupestris. Marine Ecology Progress Series. 435: 209-224.

833 Longmore, C., Trueman, C. N., Neat, C., Jorde, P. E., Knutsen, H., Stafanni, S., Catarino, C., 
834 Milton, J. A. and Mariani, S. 2014. Ocean-scale connectivity and life cycle reconstruction

835 in a deep-sea fish. Canadian Journal of Fisheries and Aquaculture Science. 71: 13128361323.

837 Lynnerup, N. Kjeldsen, H., Heegaard, S., Jacobsen, C. and Heinemeier, J. 2008. Radiocarbon 838 dating of the human eye lens crystallines reveal proteins without carbon turnover 839 throughout Life. PLOS ONE, (1), p.e1529.

840 McKinney, C. R., McCrea, J. M, Epstein, S., Allen, H. A. and Urey, H. C. 1950. Improvements in 841 mass spectrometers for the measurement of small differences in isotope abundance 842 ratios. Review of Scientific Instruments 21: 724-730.

843 Neat, F., Kynoch, R., Drewery, J. and Burns, F. 2010. Deepwater trawl survey manual. Marine $844 \quad$ Scotland-Science Report 03/10.

845 Nicol, J. A. C. 1989. The Eyes of Fishes, Oxford University Press.

846 Nielsen, J., Hedeholm, R. B., Heinemeier, J., Bushnell, P. G., Christiansen, J. S., Olsen, J., 847 Ramsey, C. B., Brill, R. W., Simon, M., Steffensen, K. F. and Steffensen, J. F. 2016. Eye lens 848 radiocarbon reveals centuries of longevity in the Greenland shark Somniosus 849 microcephalus. Science. 353(6300): 702-704.

850 Onthank, K. L. 2013. Exploring the life histories of Cephalopods using stable isotope 851 852 853 854 855 856 analysis of an archival tissue. PhD Dissertation, School of Biological Sciences, Washington State Univerity.

Parry, M. 2003. The trophic ecology of two Ommastrephid squid species, Ommastrephes bartramii and Sthenotheuthis oualaniensis, in the North Pacific sub-tropical gyre. PhD dissertation, Oceanography (Marine Biology), University of Hawaii-Manoa, Honolulu, 
857 Qi, H., Coplen, T. B., Geilmann, H., Brand, W. A., and Böhlke, J. K. 2003. Two new organic 858 reference materials for $\delta 13 \mathrm{C}$ and $\delta 15 \mathrm{~N}$ measurements and a new value for the $\delta 13 \mathrm{C}$ of 859 NBS 22 oil: Rapid Communications in Mass Spectrometry 17: 2483-2487.

860 Reum, J. C. P. 2011. Lipid correction model of carbon stable isotopes for a cosmopolitan 861 predator, spiny dogfish Squalus acanthias. Journal of fish biology. 79: 2060-2066.

862 Schartau, J. M., Sjögreen, B., Gagnon, Y. L. and Kröger, R. H. H. 2009. Optical plasticity in the 863 crystalline lenses of the cichlid fish Aequidens pulcher. Current biology: CB, 19:122864 126. (Accessed 2 September 2014).

865

866

867

Schloesser, R.W., Neilson, J.D., Secor, D.H. and Rooker, J.R. 2010. Natal origin of Atlantic bluefin tuna (Thunnus thynnus) from Canadian waters basd on otolith $\delta^{13} \mathrm{C}$ and $\delta^{18} \mathrm{O}$. Canadian Journal of Fisheries and Aquatic Science 67: 563-569

870

Thorrold, S. R., Campana, S. E., Jones, C. M. and Swart, P. K. 1997. Factors determining $\delta^{13}$ C and $\delta^{18} \mathrm{O}$ fractionation in aragonitic otoliths of marine fish. Geochimica et Cosmochimica Acta. 61: 2909-2919.

Törnroth-Horsefield, S., Hedfalk, K., Fischer, G., Lindkvist-Petersson, K. and Neutze, R. 2010. Structural insights into eukaryotic aquaporin regulation. FEBS letters, Federation of European Biochemical Societies, 584: 2580-2588.

874 875

876

Trueman, C.N., MacKenzie, K.M. and Palmer, M.R. 2012. Stable isotopes reveal linkages between ocean climate, plankton community dynamics, and survival of two populations of Atlantic salmon (Salmo salar). ICES Journal of Marine Science 69: 784794.

879

Trueman, C. N., Johnston, G., O'Hea, B and MacKenzie, K. M. 2014. Trophic interactions of fish communities at midwater depths enhance long-term carbon storage and benthic 
production on continental slopes. Proceesings of The Royal Society B. 281: 1-10.

881 Tzadik, O.E., Curtis, J.S., Granneman, J.E., Kurth, B.N., Pusack, T.J., Wallace, A.A., Hollander, 882 D.J., Peebles, E.B. and Stallings, C.D. 2017. Chemical archives in fishes beyond otoliths: 883 A review on the use of other body parts as chronological recorders of microchemical 884 constituents for expanding interpretations of enviornmental, ecological and life885 history changes. Limnology and Oceanography: Methods 15: 238-263.

886 Vaghefi, E., Walker, K., Pontre, B. P., Jacobs, M. D., Donaldson, P. J. 2012. Magnetic resonance 887 and confocal imaging of solute penetration into the lens reveals a zone of restricted 888 extracellular space diffusion. American Journal of Physiology - Regulatory, Integrative 889 and Comparative Physiology. 302: 1250-1259.

Wallace, A. A., Hollander, D. J. and Peebles, E. B. 2014. Stable isotopes in fish eye lenses as 891 potential recorders of trophic and geographic history. PloS ONE. 9(10): 1-8.

Werner, R. A. and Brand, W. A. 2001. Referencing strategies and techniques in stable isotope ratio analysis. Rapid Communications in Mass Spectrometry 15: 501-519.

Wood, C. C., Ketchen, K. S. and Beamish, R. J. 1979. Population Dynamics of Spiny Dogfish 895 896 (Squalus acanthias) in British Columbia Waters. Journal of the Fisheries Research Board 897 898 899 Tables

900 Table I - Comparison of mean lens core $\delta^{15} \mathrm{~N}$ and corrected $\delta^{13} \mathrm{C}$ values (and associated 901 standard deviations) for Aphanopus carbo, Coryphaenoides rupestris and Lamna nasus 902 (proportion resin <20\%). The stable isotope composition of pure epoxy resin is also 
903 displayed. As a measure of resin contamination of core samples, mean proportion resin

904 estimates are presented (calculated using the mass balance approach).

905

906 
Figure 1

The relationship between total length (TL) and lens diameter (LD) in four fishes

The relationship between total length (TL) and lens diameter (LD) for (A) the black scabbard fish, Aphanopus carbo, $\left(n=19, r^{2}=0.917, p=<0.001\right)$. (B) the roundnose grenadier, Coryphaenoides rupestris, $\left(n=29, r^{2}=\right.$ $0.973, p=<0.001)$. (C) the porbeagle shark, Lamna nasus $\left(n=30, r^{2}=0.901, p=<0.001\right)$. (D) the spurdog, Squalus acanthias $\left(n=101, r^{2}=0.959, p=<0.001\right)$.
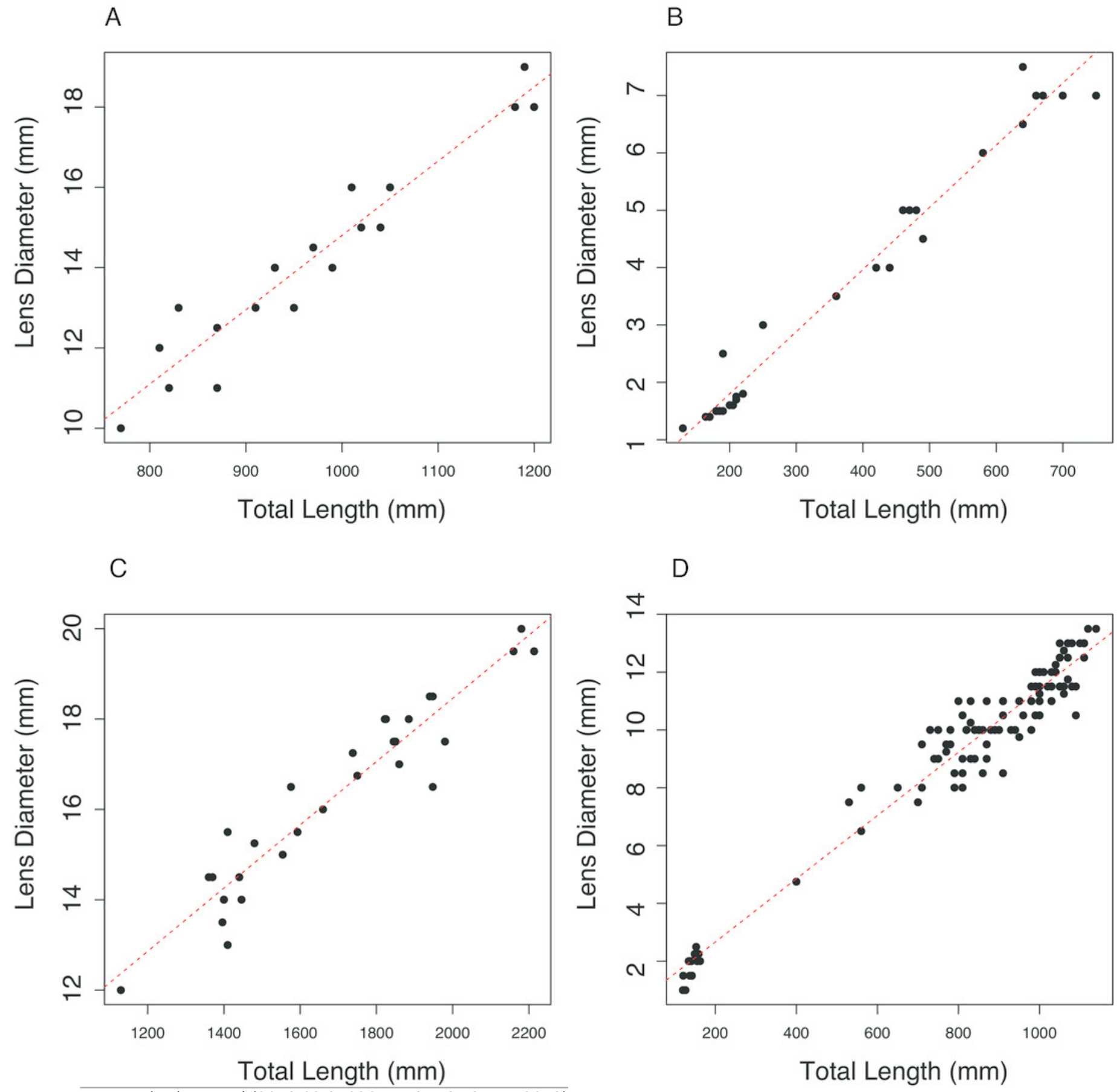


\section{Figure 2}

Thin sections of teleost and elasmobranch lenses embedded in pigmented Epoxy resin.

(A) black scabbardfish (Aphanopus carbo). (B) monkfish (Lophius americanus). (C) cod (Gadus morhua). (D) conger eel (Conger conger). (E) hake (Merluccius merluccius). (F) haddock (Melanogrammus aeglefinus). (G) porbeagle (Lamna nasus). (H) spurdog (Squalus acanthias). (I) blue shark (Prionace glauca). (J) oceanic white-tip shark (Carcharhinus longimanus). White lines are $5 \mathrm{~mm}$ scale bars.

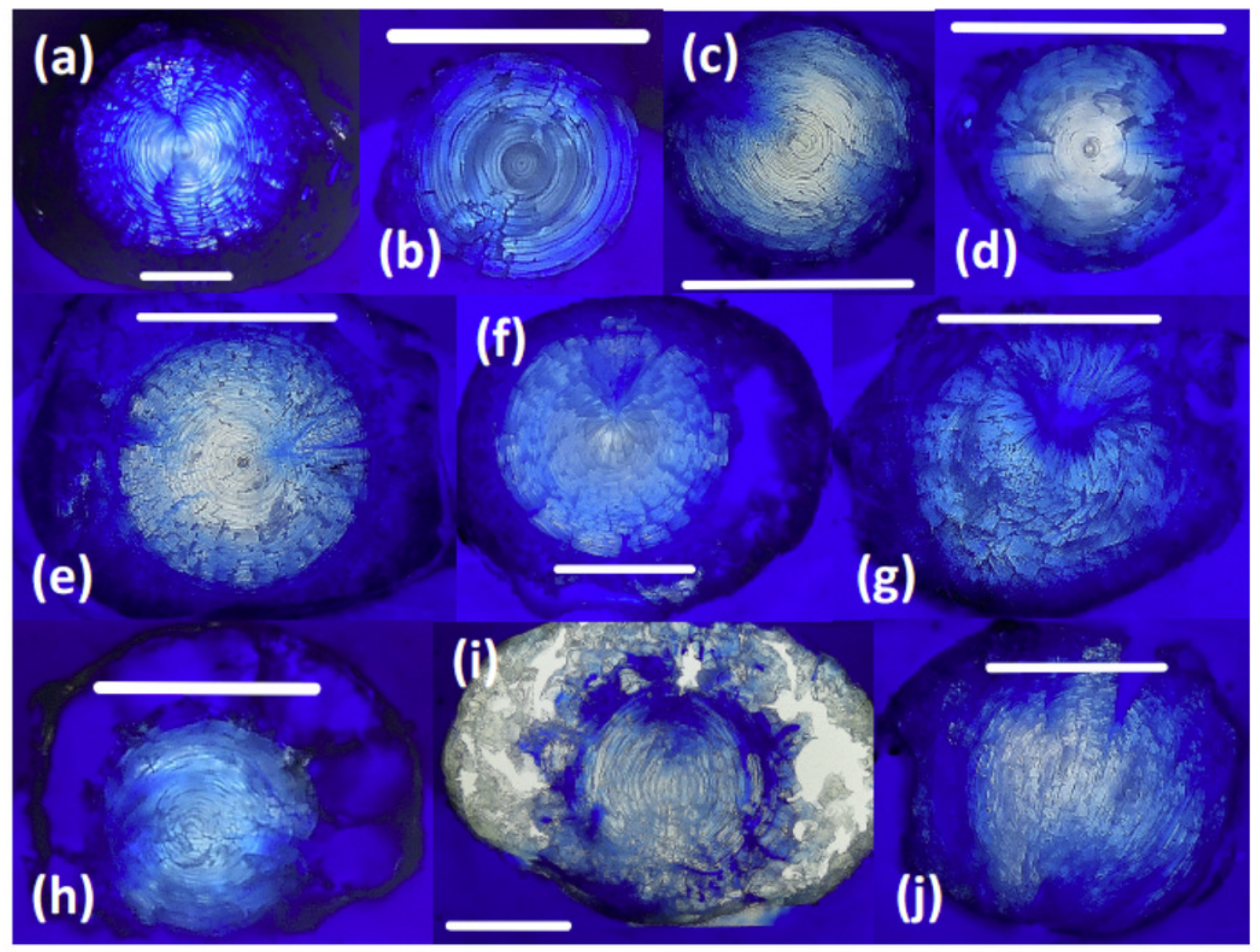


Figure 3

Bivariate plots of $\delta^{15} \mathrm{~N}$ (blue) and $\delta^{13} \mathrm{C}$ (red) variability through Aphanopus carbo lenses.

The corresponding estimate of individual fish total length at time of tissue formation was recovered from relationship shown in Figure 1(A), and the location of the sample from the lens transect.
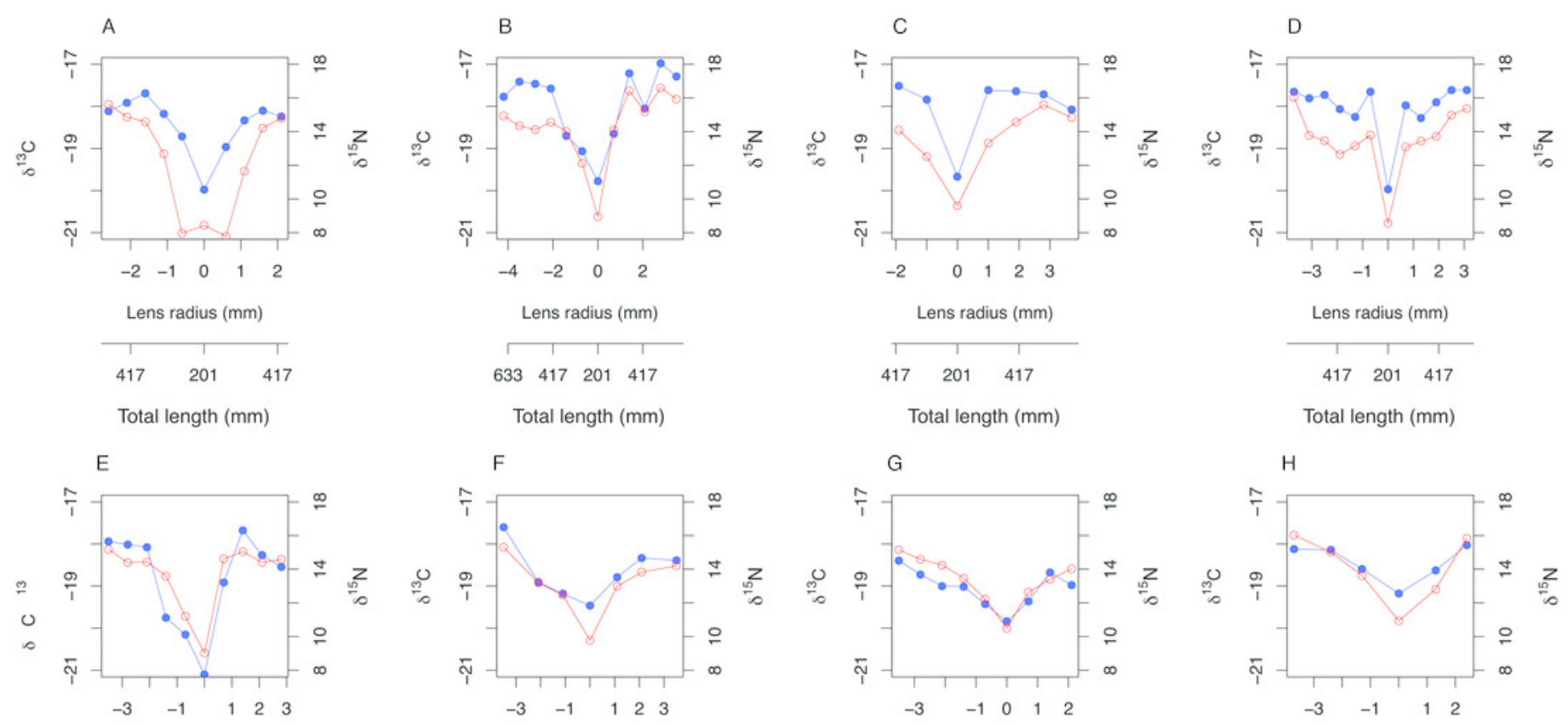

Lens radius (mm)

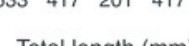

Total length (mm)

$417 \quad 201 \quad 417$

Total length (mm)
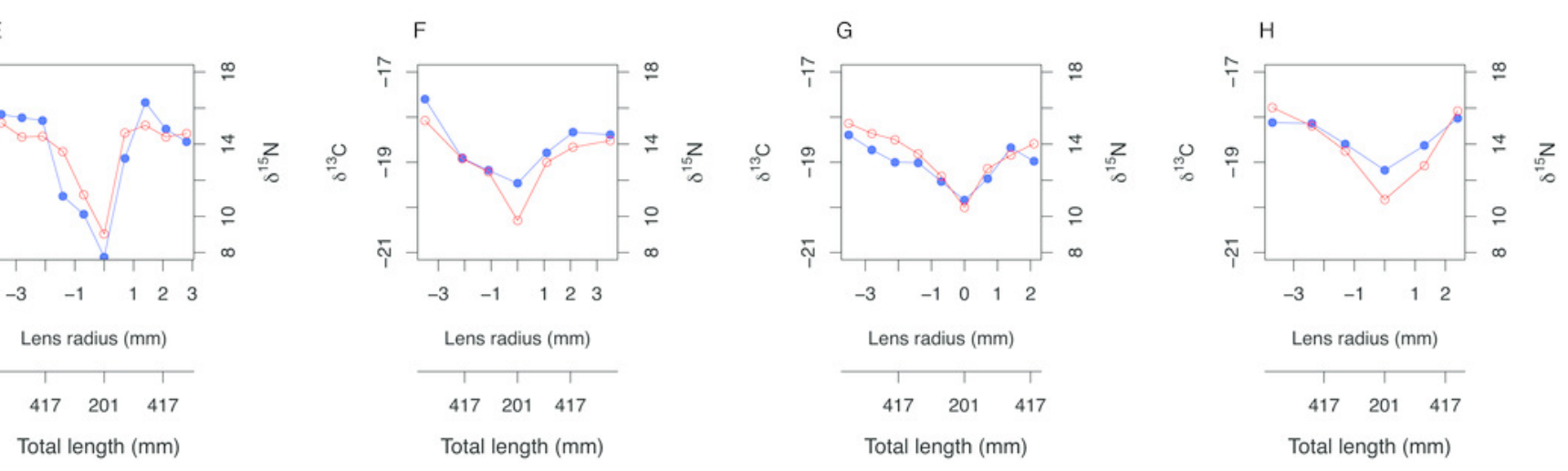

$\begin{array}{lll}-3 & -1 & 1\end{array}$

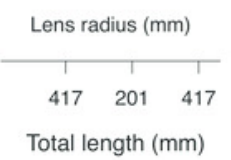


Figure 4

Stable isotope compositions of lens tissues between species

Comparison of lens core $\delta^{13} \mathrm{C}$ and $\delta^{15} \mathrm{~N}$ values for Coryphanoides rupestris, Aphanopus carbo and Lamna nasus. Error bars show standard deviation.

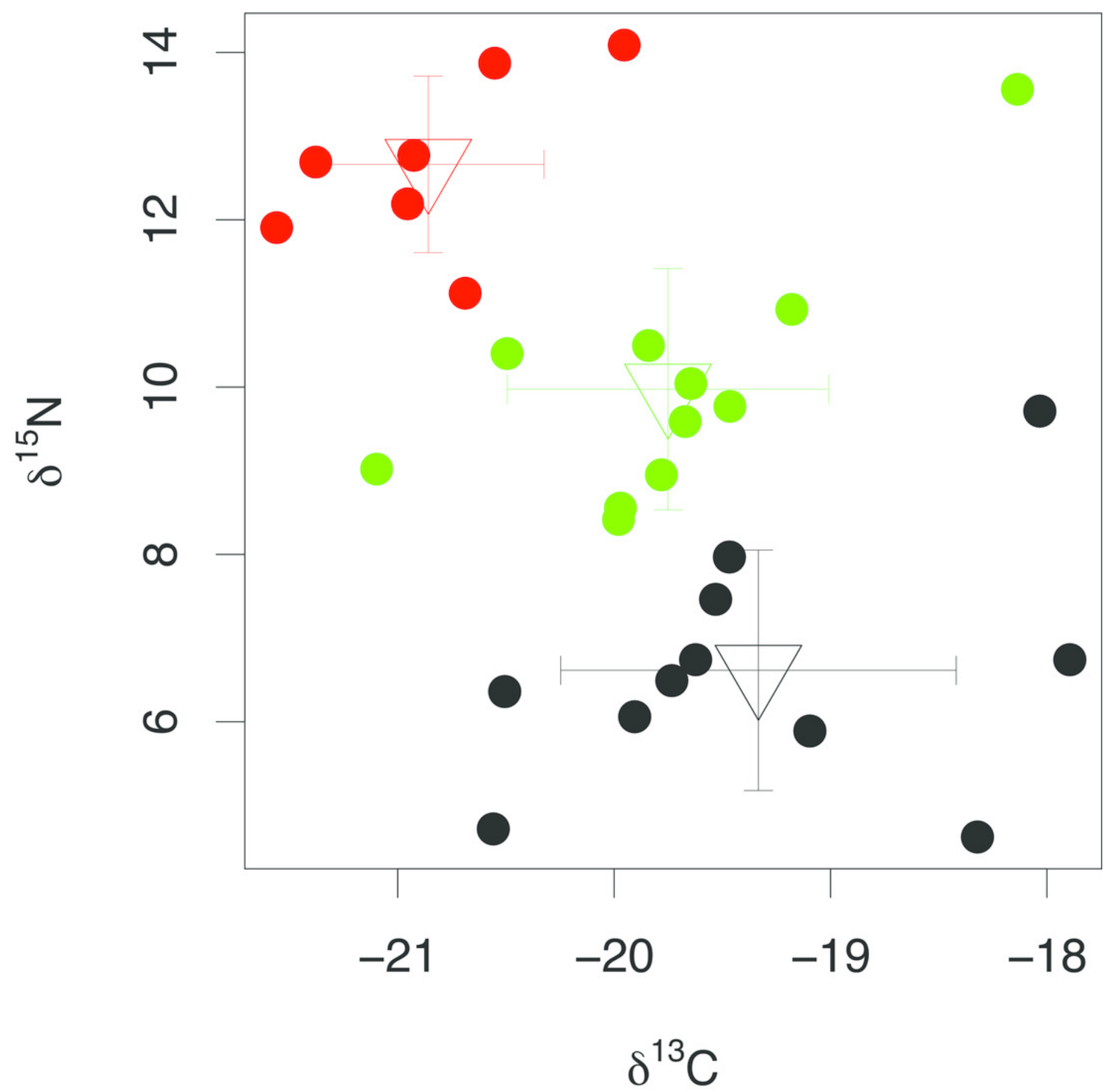


Figure 5

Tissue-specific differences in isotopic compositions in embryonic sharks

Comparison of lens and muscle $\delta^{13} \mathrm{C}(\mathrm{A})$ and $\delta^{15} \mathrm{~N}$ (B) values from 19 Squalus acanthias embryos.

A

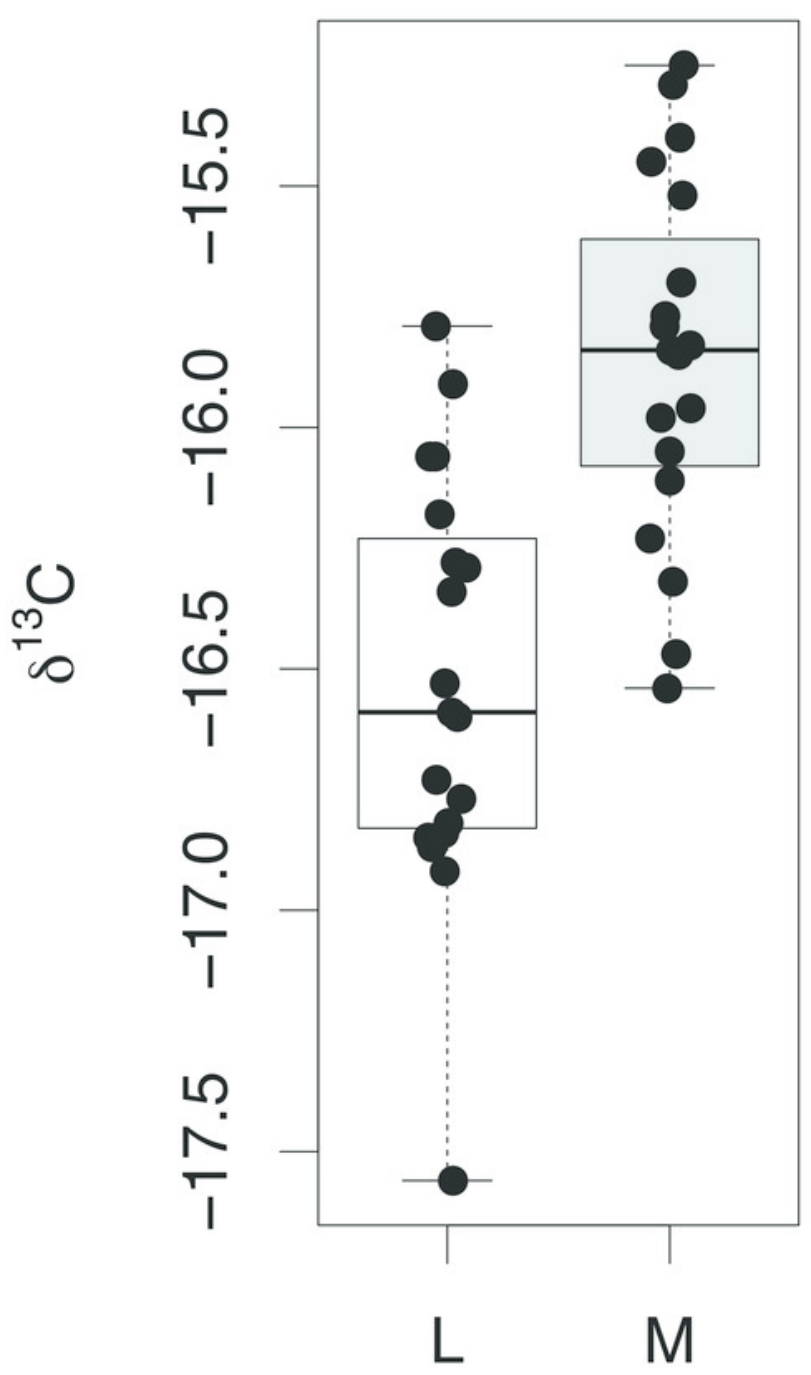

B

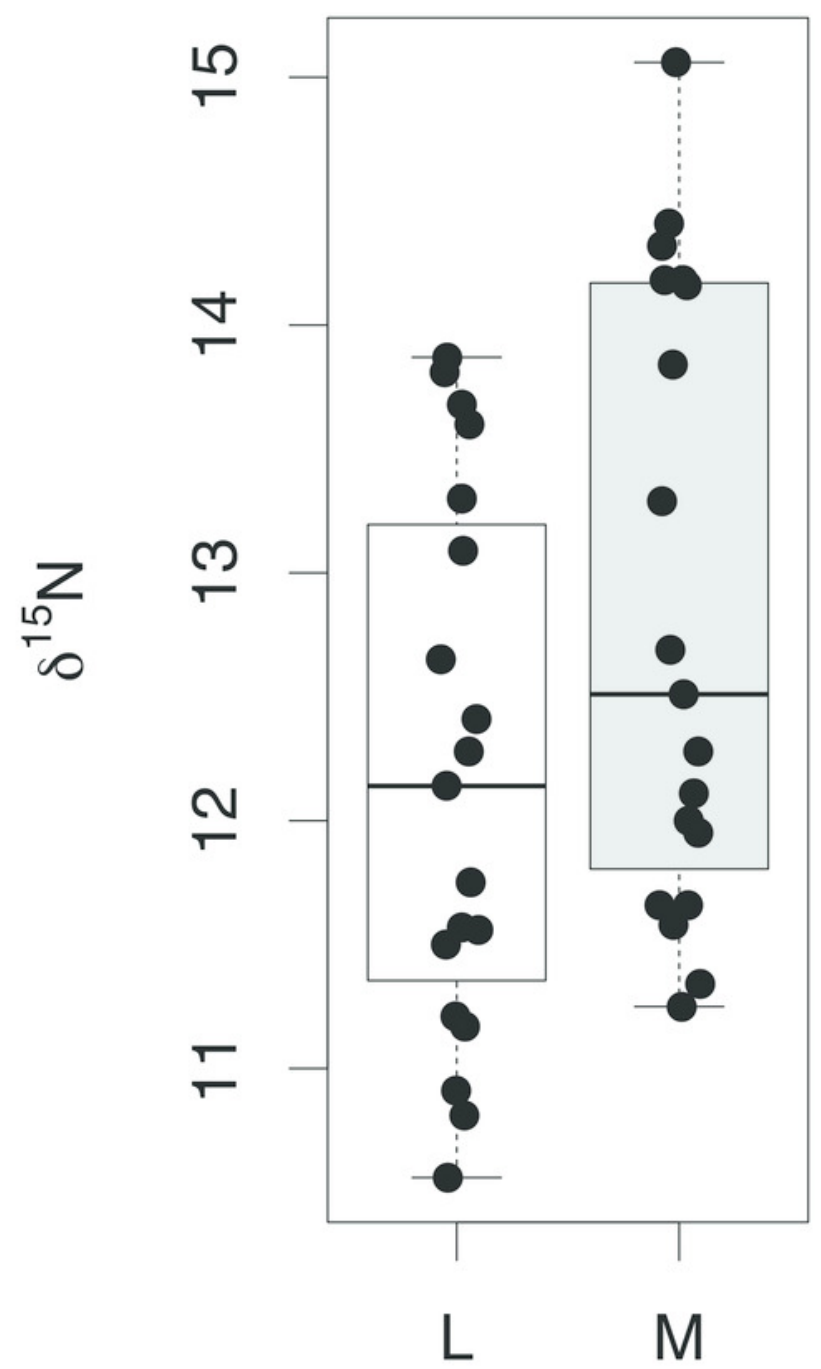


Figure 6

Tissue-specific differences in isotopic compositions in larval and adult fish

Comparison of lens core and muscle $\delta^{13} \mathrm{C}(\mathrm{A})$ and $\delta^{15} \mathrm{~N}(\mathrm{~B})$ values from Coryphaenoides

rupestris specimens measuring $\leq 50 \mathrm{~mm}$. Eye lenses and muscle samples were obtained from specimens caught during the deep-water survey onboard MRV Scotia; lenses were excised from fish caught in September 2012, and the muscle originates from specimens caught during September 2013.

A

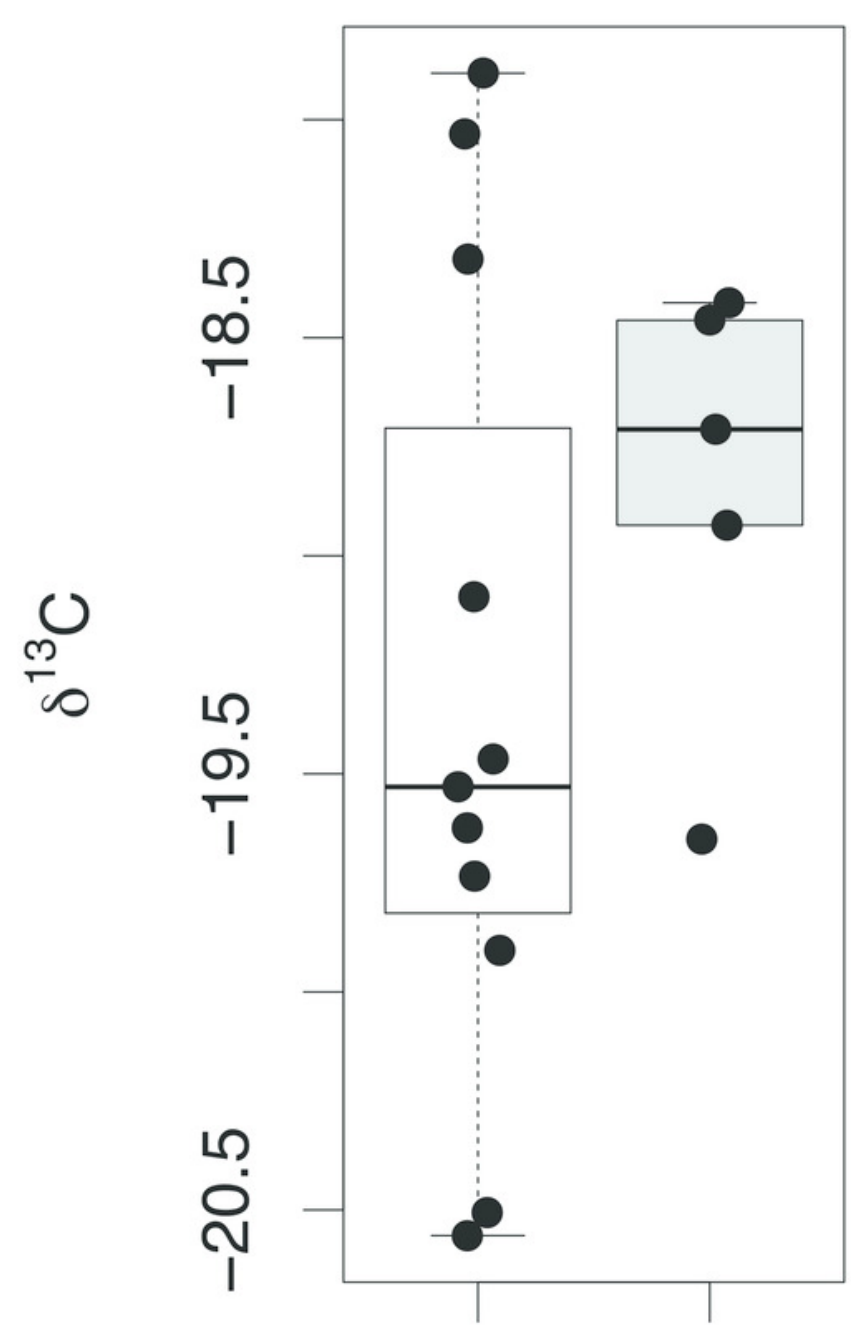

Lens
B

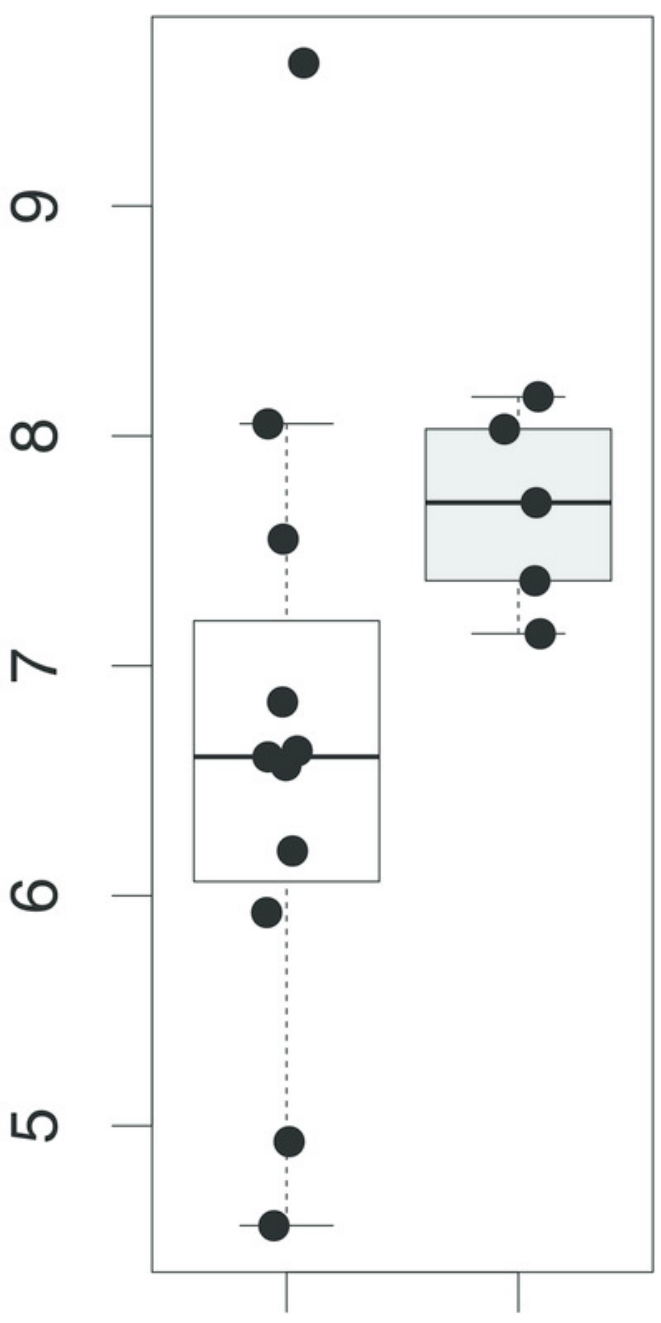

Lens 


\section{Table $\mathbf{1}$ (on next page)}

Effect of resin contamination on stable isotope compositions of sectioned eye lens proteins

Comparison of mean lens core $\delta^{15} \mathrm{~N}$ and corrected $\delta^{13} \mathrm{C}$ values (and associated standard deviations) for Aphanopus carbo, Coryphaenoides rupestris and Lamna nasus (proportion resin $<20 \%$ ). The stable isotope composition of pure epoxy resin is also displayed. As a measure of resin contamination of core samples, mean proportion resin estimates are presented (calculated using the mass balance approach). 
1

\begin{tabular}{|l|l|l|l|l|l|l|l|}
\hline & \multirow{2}{*}{ Pure resin } & \multicolumn{2}{|l|}{ A. carbo (n=11) } & \multicolumn{2}{l|}{ C. rupestris (n=11) } & \multicolumn{2}{l|}{ L. nasus (n=6) } \\
\cline { 3 - 8 } & & Mean & SD & Mean & SD & Mean & SD \\
\hline$\delta^{15} \mathbf{N}$ & -2.28 & 9.98 & 1.44 & 6.83 & 1.57 & 12.74 & 1.13 \\
\hline$\delta^{13}$ C (corrected) & -29.49 & -20.70 & 0.72 & -19.17 & 0.84 & -18.14 & 0.77 \\
\hline Prop. Resin & NA & 0.12 & 0.07 & 0.12 & 0.08 & 0.13 & 0.26 \\
\hline
\end{tabular}

2

3 